\title{
Uncertainties in the assessment of the isotopic composition of surface fluxes: A direct comparison of techniques using laser-based water vapor isotope analyzers
}

Stephen P. Good, ${ }^{1}$ Keir Soderberg, ${ }^{1}$ Lixin Wang, ${ }^{2,3}$ and Kelly K. Caylor ${ }^{1}$

${ }^{1}$ Department of Civil and Environmental

Engineering, Princeton University,

Princeton, New Jersey, USA.

${ }^{2}$ School of Civil and Environmental

Engineering, University of New South

Wales, Australia

${ }^{3}$ Department of Earth Sciences, Indiana

University-Purdue University, Indianapolis

(IUPUI), Indianapolis, Indiana, USA

This is the author's manuscript of the article published in final edited form as:

Good, S. P., Soderberg, K., Wang, L., \& Caylor, K. K. (2012). Uncertainties in the assessment of the isotopic composition of surface fluxes: A direct comparison of techniques using laser-based water vapor isotope analyzers. Journal of Geophysical Research: Atmospheres (1984-2012), 117(D15).

http://dx.doi.org/10.1029/2011JD017168 
X - 2 GOOD, SODERBERG, WANG, \& CAYLOR: UNCERTAINTY IN MEASUREMENTS OF $\delta_{E T}$

${ }_{5}$ Abstract. The isotopic composition of surface fluxes is a key environ-

6 mental tracer currently estimated with variety of methods, including: Keel-

7 ing mixing models, the flux gradient technique, and eddy covariance. We present

8 a direct inter-comparison of these three methods used to estimate the iso-

9 topic ratio of water vapor in surface fluxes $\left(\delta_{E T}\right)$ over half-hour periods, with

10 a focus on the statistical uncertainty of each method $\left(\sigma_{\delta_{E T}}\right)$. We develop ex-

${ }_{11}$ pressions for $\sigma_{\delta_{E T}}$ as a function of instrument precision, sample size, and at-

${ }_{12}$ mospheric conditions. Uncertainty estimators are validated with high frequency

${ }_{13}(1 \mathrm{~Hz})$ data from multiple configurations of commercial off-axis integrated

${ }_{14}$ cavity output spectroscopy (ICOS) systems. We find measurement techniques

utilizing the high frequency capabilities of ICOS system outperform those methods where a single average of the isotopic composition is obtained at each height, with improvements attributed to large sample counts and increased variation in observed concentrations. Analytically, and with supporting data, we show that over 30 minute periods the Keeling plot and flux-gradient techniques produce nearly identical $\delta_{E T}$ and $\sigma_{\delta_{E T}}$ values, while eddy covariance calculations always introduce more uncertainty given the same high frequency data. This additional uncertainty is proportional to the reciprocal of the correlation coefficient between vertical wind speed and water vapor mixing ratio. Finally, given the inverse relationship between $\delta_{E T}$ uncertainties and the range of water vapor observed, we propose that experimental designs should attempt to maximize both sample count and the coefficient of variation in atmospheric water vapor. 
GOOD, SODERBERG, WANG, \& CAYLOR: UNCERTAINTY IN MEASUREMENTS OF $\delta_{E T} \quad \mathrm{X}-3$

\section{AGU manuscript submission information for JGR-A:}

28

29

30

31

32

33

34

35

36

37 None

38

39

40

41

42

43

44

${ }_{45}$ 3-Eddy covariance method results in larger uncertainty in isotope fluxes 
X - 4 GOOD, SODERBERG, WANG, \& CAYLOR: UNCERTAINTY IN MEASUREMENTS OF $\delta_{E T}$

\section{Introduction}

The isotopic composition of surface fluxes can be a powerful tracer for understanding ocean and land surface interactions with the atmosphere at multiple scales. Globally, geological research such as paleoclimate studies are partially constrained by the ${ }^{18} \mathrm{O} /{ }^{16} \mathrm{O}$ enrichment of atmospheric oxygen with respect to ocean water known as the Dole effect [Hoffmann et al., 2004]. At the regional and watershed scales, knowledge of isotope fluxes facilitates hydrological studies, such as the quantification of continental rainfall recycling [Risi et al., 2010] or estimates of lake evaporation [Gibson et al., 1993]. For biological investigations, the isotopic composition of surface fluxes provides a tracer of both water vapor and carbon dioxide exchanges [Yakir and Wang, 1996; Yakir and Sternberg, 2000; Wingate et al., 2009, 2010; Barbour et al., 2011; Griffis et al., 2011] and allows for the quantification of specific components of ecosystem processes such as plant transpiration and respiration [Brunel et al., 1992; Wang and Yakir, 2000; Ogée et al., 2004; Wang et al., 2012].

The focus of this manuscript is on uncertainties in measurement of the isotopic composition of evapotranspiration over a heterogenous vegetated landscape, $\delta_{E T}[\% 0]$, though our results are generalizable to the flux composition of other isotopes. The value of $\delta_{E T}$, often expressed in delta notation (per mil [\%o], cf. section 2 for def.), is a representation of the ratio of the surface flux of water vapor containing rare isotopes, e.g., ${ }^{2} \mathrm{H}^{1} \mathrm{H}^{16} \mathrm{O}$ or ${ }^{1} \mathrm{H}^{1} \mathrm{H}^{18} \mathrm{O}$, to the surface flux of water vapor containing the abundant isotope, e.g., ${ }^{1} \mathrm{H}^{1} \mathrm{H}^{16} \mathrm{O}$. The isotopic composition of surface water vapor flux is composed of information from two components: transpiration from leaves $\left(\delta_{T}\right)$ and evaporation from soils or standing water 
GOOD, SODERBERG, WANG, \& CAYLOR: UNCERTAINTY IN MEASUREMENTS OF $\delta_{E T} \quad \mathrm{X}-5$

${ }_{67}\left(\delta_{E}\right)$. The value of $\delta_{T}$ is the result of complex interactions between liquid water at the leaf

evaporation site, ambient atmospheric water vapor, leaf water status, and environmental conditions outside the leaf [Farquhar et al., 2007; Ogée et al., 2007]. The value of $\delta_{E}$, however, is a physically controlled process, often heavily depleted relative to the source water isotope composition and is commonly estimated following the model of Craig and Gordon [1965]. The Craig and Gordon [1965] model incorporates humidity, temperature, kinetic effects, equilibrium isotope fractionation, and the isotope compositions of both liquid water at the evaporation surface and atmospheric water vapor. Combined with estimates of $\delta_{T}$ and $\delta_{E}, \delta_{E T}$ can be used to estimate the contribution of transpiration and evaporation to surface vapor flux across multiple spatial scales [Yepez et al., 2003; Williams et al., 2004; Wang et al., 2010].

Multiple methods have arisen to estimate $\delta_{E T}$, especially as laser-based isotope instruments capable of making continuous measurements of water vapor $\delta^{2} \mathrm{H}$ and $\delta^{18} \mathrm{O}$ with precision similar to traditional cryogenic-based methods have become available [Wen et al., 2008; Gupta et al., 2009; Lee et al., 2009; Wang et al., 2009, 2010]. Traditionally, the value of $\delta_{E T}$ has been estimated using a Keeling [1958] mixing model approach, which is a based on a relationship between the inverse of water vapor concentration and stable isotope composition within the boundary layer. It should be emphasized that the assumptions of only two isotope sources in the Keeling plot, as well as the extrapolation of regression beyond the observed data are noted drawbacks to the Keeling plot approach [Yakir and Sternberg, 2000; Pataki et al., 2003; Zobitz et al., 2006]. Such assumptions were part of the original motivation for the present study. Other potential methods of estimating $\delta_{E T}$ include the flux gradient method [Yakir and Wang, 1996] and relaxed eddy accumulation [Guenther 
X - 6 GOOD, SODERBERG, WANG, \& CAYLOR: UNCERTAINTY IN MEASUREMENTS OF $\delta_{E T}$

90

et al., 1996; Bowling et al., 1999]. Recent studies have shown the possibility of directly estimating isotope fluxes through coupling eddy covariance and continuous isotope monitoring [Saleska et al., 2006; Griffis et al., 2008, 2010; Sturm et al., 2012]. Despite sustained interest in $\delta_{E T}$ estimation there are few studies comparing the performance and associated uncertainty of alternative methods while exploring the applicability of each method under different instrumental configurations.

The development of methodologies to assess $\delta_{E T}$ at time scales on the order of minutes is necessary for accurate understanding of the isotopic interactions between the atmosphere and surface. Non-stationarity of surface and micro-meteorological conditions has long been [Businger, 1986; Stull, 1988; Kaimal and Finnigan, 1994; Baldocchi, 2003; Lee et al., 2004] and continues to be [Gu et al., 2012] an important issue in estimation of turbulent fluxes. The importance of stationary conditions has driven the global flux community to conduct analysis at short time scales (typically 30 minute averaging blocks) and remove non-stationary intervals from analysis [Foken and Wichura, 1996]. These issues clearly affect isotopic fluxes, where diurnal leaf water enrichment [Farquhar and Cernusak, 2005], atmospheric advection and entrainment [Lee et al., 2006, 2011], and other non-stationarities have been recognized as significant problems with analysis conducted at scales of hours or days. laser-based measurements [Griffis et al., 2008, 2010; Sturm et al., 2012; Santos et al., In Press] and intensive sampling campaigns [Bowling et al., 2003] that conduct analysis over short timescales are rare in the isotope literature, yet needed to accurately assess surface atmosphere flux composition.

Because each method has its own advantages and inherent assumptions, detailed intermethod comparisons are needed to improve decision making when choosing and utilizing 
GOOD, SODERBERG, WANG, \& CAYLOR: UNCERTAINTY IN MEASUREMENTS OF $\delta_{E T} \quad \mathrm{X}-7$

a specific method for $\delta_{E T}$ estimation. Bowling et al. [2003] examined the flux gradient, relaxed eddy accumulation and an indirect eddy covariance technique developed from the relationship between carbon flux and $\delta^{13} \mathrm{C}$ values using flask and flexible bag collectors, with isotope analysis conducted on a mass spectrometer. They report that over the course of the diurnal cycle, consistent isotopic flux results were obtained among the methods [Bowling et al., 2003]. Additional studies [Griffis et al., 2004, 2005] compared the Keeling plot and flux gradient methods for isotopic fluxes of $\delta^{13} \mathrm{C}$ and $\delta^{18} \mathrm{O}$ with a tunable diode laster absorption spectroscopy system. These studies found good agreement between the Keeling plot and flux gradient technique, however, later studies found significant differences [Zhang et al., 2006; Griffis et al., 2007]. Sturm et al. [2012] examined carbon isotope fluxes using quantum cascade laser absorption spectrometry, comparing the Keeling plot with the eddy covariance technique, and found discrepancies between these different methods. The recent inter-method comparison of Santos et al. [In Press] assessed flux isotopic composition over 30 minute periods using a tunable diode laser system with the Keeling plot, flux-gradient, and a Lagrangian dispersion method. This study found high correlation between the Keeling plot and flux-gradient results with mean values statistically identical, however more half-hour intervals met their quality control criteria for flux-gradient method then for the Keeling plot method [Santos et al., In Press].

The observed differences in estimates due to divergent methodologies requires a critical examination of the uncertainties inherent in each technique. The uncertainty in Keeling plots was analyzed by Pataki et al. [2003], Zobitz et al. [2006] and Kayler et al. [2010], with a focus on the consequences of regression model choice. Zhang et al. [2006] reported larger uncertainties for flux gradient regressions than for the Keeling plots, with Griffis et al. 
X - 8 GOOD, SODERBERG, WANG, \& CAYLOR: UNCERTAINTY IN MEASUREMENTS OF $\delta_{E T}$ 
GOOD, SODERBERG, WANG, \& CAYLOR: UNCERTAINTY IN MEASUREMENTS OF $\delta_{E T} \quad \mathrm{X}-9$

We assess three methods for estimating the isotopic composition of surface fluxes: Keeling plot (KP), flux gradient (FG), and eddy covariance (EC). Although we examine the surface flux of water vapor, the same methods have been utilized for the fluxes of other compounds, particularly carbon dioxide [Keeling, 1958; Yakir and Wang, 1996; Griffis et al., 2008]. Isotopic composition is expressed in $\delta$ notation, $\delta=\left(R / R_{s t d}-1\right)$ [\%o], where $R$ is the ratio of rare $(\alpha)$ to abundant $(\beta)$ isotopes (e.g., ${ }^{18} \mathrm{O}$ and ${ }^{16} \mathrm{O}$ respectively) and $R_{s t d}$ refers to the ratio in Vienna Standard Mean Ocean Water (VSMOW) [De Laeter et al., 2003]. Per mil refers to one part per thousand parts, with a value of $10^{-3}$ and is represented by \%o [Coplen, 2011]. A concise review of assessed techniques follows.

\subsection{Keeling plot methods (KP)}

Keeling [1958] used the observed correlation between variation in $\delta^{13} \mathrm{C}$ and $\mathrm{CO}_{2}$ concentrations in coastal air samples to determine the sources of elevated $\mathrm{CO}_{2}$ in the atmosphere. The method has been employed frequently since 1958 over a variety of terrains, notably forests and agricultural sites [Yakir and Sternberg, 2000; Williams et al., 2004; Griffis et al., 2004; Yepez et al., 2005; Wang et al., 2010]. Based on a two end-member mixing model, Keeling [1958] assumed that the scalar concentration at the measurement location is a mixture of the scalar concentration present in the atmospheric boundary layer and the contribution from a local source. A key assumption is that the isotopic composition of both the source and background are constant. The spatial heterogeneity of isotope sources thus is a key factor in the reliability of Keeling plots, and spatial variation in isotope signatures, such as those arising from the interaction between $\mathrm{CO}_{2}$ and leaf water, necessitates caution when applying the Keeling plot method [Ogée et al., 2004]. As noted by Lee et al. [2011], the Keeling mixing model also does not account for entrainment of 
X - 10 GOOD, SODERBERG, WANG, \& CAYLOR: UNCERTAINTY IN MEASUREMENTS OF $\delta_{E T}$

as:

$$
\delta_{v} \chi_{v}=\delta_{a b l} \chi_{a b l}+\delta_{E T} \chi_{E T},
$$

where $\chi_{v}\left[\mathrm{~mol} \mathrm{H}_{2} \mathrm{O}\right.$ mol Dry Air $\left.{ }^{-1}\right]$ is the molar mixing ratio of water vapor with respect to dry air measured at the sampling height. Noting that moisture at the measurement location must come from both the above air mass as well as the surface, (i.e., $\chi_{v}=\chi_{a b l}+\chi_{E T}$ ), equation (1) can be rearranged as:

$$
\delta_{v}=\delta_{E T}+\chi_{a b l}\left(\delta_{a b l}-\delta_{E T}\right) \frac{1}{\chi_{v}} .
$$

In practice, equation (2) is expressed as line defined by a constant intercept, $A_{K P}$, and slope, $B_{K P}$, as:

$$
\delta_{v}=A_{K P}+B_{K P} \frac{1}{\chi_{v}} .
$$


GOOD, SODERBERG, WANG, \& CAYLOR: UNCERTAINTY IN MEASUREMENTS OF $\delta_{E T} \quad \mathrm{X}-11$

\subsection{Flux gradient (FG) profile technique}

Based on Monin and Obukhov [1954] similarity theory and further developed by Businger et al. [1971], the flux gradient method estimates constituent fluxes based on vertical gradients of scalar concentrations in the atmospheric surface layer [Yakir and Wang, 1996; Bowling et al., 2003; Griffis et al., 2004, 2005]. For evapotranspired water vapor, the flux, $F_{E T}\left[\mathrm{~mol} \mathrm{~m}^{-2} \mathrm{~s}^{-1}\right]$, is proportional to measured changes in molar mixing ratio of water vapor, $\Delta \chi_{v}$, with height, $\Delta z[\mathrm{~m}]$, such that

$$
F_{E T}=-K \frac{\overline{\rho_{a}}}{M_{a}} \frac{\Delta \chi_{v}}{\Delta z}
$$

where $\rho_{a}\left[\mathrm{~kg} \mathrm{~m}^{-3}\right]$ is the density of dry air, $M_{a}\left[\mathrm{~kg} \mathrm{~mol}^{-1}\right]$ is the molecular weight of dry air, and $K\left[\mathrm{~m}^{2} \mathrm{~s}^{-1}\right]$ is the eddy diffusivity of water vapor. Equation (4) is then written for both the rare $(\alpha)$ and abundant $(\beta)$ isotopes, making the assumption that eddy diffusivities, dry air density, and vertical locations are the same for each isotopologue. The isotopic composition of evapotranspired water is simply the ratio $R_{E T}={ }^{\alpha} F_{E T} /{ }^{\beta} F_{E T}$, which can be expressed in $\delta$ notation as:

$$
\delta_{E T}=\left(\frac{{ }^{\alpha} F_{E T} /{ }^{\beta} F_{E T}}{R_{s t d}}-1\right),
$$

where ${ }^{\alpha} F_{E T}$ refers to the flux of the rare isotope and ${ }^{\beta} F_{E T}$ refers to the flux of the abundant isotope found using equation (4) [Griffis et al., 2004, 2005]. When estimating the surface flux isotope ratio over short time periods (i.e $\leq 1 \mathrm{hr}$ ), and not the flux of individual 
X - 12 GOOD, SODERBERG, WANG, \& CAYLOR: UNCERTAINTY IN MEASUREMENTS OF $\delta_{E T}$

isotopologues themselves, the flux gradient method simplifies considerably because the eddy diffusivity parameter, $K$, is assumed constant and cancels out [Griffis et al., 2007; Drewitt et al., 2009]. The value of $R_{E T}$ is then equal to $\Delta^{\alpha} \chi_{v} / \Delta^{\beta} \chi_{v}$, which is the slope, $B_{F G}$, of the regression of ${ }^{\alpha} \chi_{v}$ against ${ }^{\beta} \chi_{v}$ as:

$$
{ }^{\alpha} \chi_{v}=A_{F G}+B_{F G}{ }^{\beta} \chi_{v} .
$$

Monin and Obukhov [1954] similarity theory has been shown to break down in the roughness sublayer at the bottom of the boundary layer where vegetation interacts directly with turbulent air flow. This departure from standard behavior results in changes in eddy diffusion coefficients, and flux gradient measurements must be made well above this region [Businger, 1986; Kaimal and Finnigan, 1994]. The depth of the roughness sublayer increases with the size and complexity of vegetation structure, thus many isotope flux studies employing this method have been conducted over uniform agricultural fields (e.g., [Griffis et al., 2004]). The difficulty in measuring small vertical gradients during unstable conditions is another drawback inherent to this methodology [Businger, 1986; Sturm et al., $2012]$.

Through simple algebraic manipulation it is easily demonstrated that the flux gradient estimate of $\delta_{E T}$ derived from the slope $B_{F G}$ is nearly identical to the intercept of the regression from the Keeling plot $\left(A_{K P}\right)$. This is shown by dividing equation $(6)$ by ${ }^{\beta} \chi_{v} R_{s t d}$, and noting that $B_{F G}=\left(\delta_{E T}+1\right) R_{s t d}$ from equation (5). The result is then solved for $\delta_{v}=\left(\frac{{ }^{\alpha} \chi_{v} /{ }^{\beta} \chi_{v}}{R_{s t d}}-1\right)$, leaving

$$
\delta_{v}=\delta_{E T}+\left(A_{F G} / R_{s t d}\right) \frac{1}{{ }^{\beta} \chi_{v}},
$$


GOOD, SODERBERG, WANG, \& CAYLOR: UNCERTAINTY IN MEASUREMENTS OF $\delta_{E T} \quad \mathrm{X}-13$

which is approximately equal to equation (3). Given that the same data are used and that all assumptions are met for each method, both the Keeling plot and flux gradient methods will produce identical estimates of the isotopic composition of the surface flux. This result is expected since both techniques are based on a linear regression of the same data, ${ }^{\alpha} \chi_{v}$ and ${ }^{\beta} \chi_{v}$, as $\delta_{v}$ is directly determined from the ratio of the two isotope mixing ratios and the $\chi_{v}$ is approximately equal to ${ }^{\beta} \chi_{v}$. Kammer et al. [2011] also observed this close similarity, finding that the flux gradient and Keeling plot results have negligible differences when $R_{E T}$ is determined from the slope of a regression between the rare and abundant isotopologues over short averaging intervals (400 seconds). Figure 2 provides an example of different flux gradient plots for a typical half hour time period.

\subsection{Eddy covariance (EC)}

Eddy covariance techniques are employed worldwide in global networks (AmeriFlux, CarboEurope, AsiaFLUX, CarboAfrica, etc.) as the standard method for estimating the atmospheric exchange of water, carbon and energy with the surface [Lee et al., 2004]. Eddy covariance resolves fluxes by examination of the co-variation between high frequency $(\geq 1 \mathrm{~Hz})$ scalar concentrations and vertical wind speeds. Recently Griffis et al. [2008, 2010] have utilized high frequency isotope measurements from laser-based analyzers to estimate the flux of of carbon and oxygen isotopes. The flux of each isotope is calculated as the average (denoted by overbars) product of deviations from mean values (denoted by primes) of individual isotope mixing ratios, ${ }^{\alpha} \chi_{v}$ and ${ }^{\beta} \chi_{v}$, and vertical wind speeds $w\left[\mathrm{~m} \mathrm{~s}^{-1}\right]$, as

$$
{ }^{\alpha} F_{E T}=\frac{\overline{\rho_{a}}}{M_{a}} \overline{w^{\prime \alpha} \chi_{v}^{\prime}} \quad \text { and } \quad{ }^{\beta} F_{E T}=\frac{\overline{\rho_{a}}}{M_{a}} \overline{w^{\prime \beta} \chi_{v}^{\prime}} .
$$


X - 14 GOOD, SODERBERG, WANG, \& CAYLOR: UNCERTAINTY IN MEASUREMENTS OF $\delta_{E T}$

$$
\begin{aligned}
I_{E T} & =\frac{\rho_{a}}{M_{a}} \overline{\left(\bar{w}+w^{\prime}\right)\left(\overline{\chi_{v}}+\chi_{v}^{\prime}\right)\left(\overline{\delta_{v}}+\delta_{v}^{\prime}\right)} \\
& =\frac{\rho_{a}}{M_{a}}\left(\overline{\delta_{v}} \overline{w^{\prime} \chi_{v}^{\prime}}+\overline{\chi_{v}} \overline{w^{\prime} \delta_{v}^{\prime}}+\overline{\chi_{v}^{\prime} w^{\prime} \delta_{v}^{\prime}}\right) .
\end{aligned}
$$

Where the standard cancelations of average deviations from the average are employed. The product of the three deviations, $\overline{\chi_{v}^{\prime} w^{\prime} \delta_{v}^{\prime}}$, is orders of magnitude smaller than all other terms and considered zero. Additionally, the isotopic composition of the flux is independent of the flux magnitude, such that $\overline{F_{E T} \delta_{E T}}=F_{E T} \delta_{E T}$. By dividing equation (10) by the standard EC flux, $F_{E T}=\frac{\rho_{a}}{M_{a}} \overline{w^{\prime} \chi_{v}^{\prime}}$, we can express $\delta_{E T}$ as:

$$
\delta_{E T}=\frac{\overline{\chi_{v}}}{\overline{w^{\prime} \chi_{v}^{\prime}}} \overline{w^{\prime} \delta_{v}^{\prime}}+\overline{\delta_{v}}
$$

where the term $\overline{w^{\prime} \delta_{v}^{\prime}}\left[\% 0 \mathrm{~m} \mathrm{~s}^{-1}\right]$ is known as the isoforcing [Lee et al., 2009]. Equation (11) is simply a restatement of equation (8) from Lee et al. [2009]. Figure 2 provides examples of eddy covariance plots for a typical half hour time period. 
GOOD, SODERBERG, WANG, \& CAYLOR: UNCERTAINTY IN MEASUREMENTS OF $\delta_{E T} \quad \mathrm{X}-15$

\section{Estimation of flux uncertainty}

There are many possible sources of error in measurements of surface fluxes, and these errors arise either due to random processes or systematic observation issues [Businger, 1986]. Systematic errors lead to bias in measurement results and attempts are made to correct these by ensuring proper instrument configuration and post processing techniques [Billesbach, 2010]. Coordinate rotations [Lee et al., 2004] and frequency response corrections [Moore, 1986; Lenschow and Raupach, 1991] as well as quality control filtering of non-stationary data periods [Foken and Wichura, 1996] are often employed to remove systematic bias in observed fluxes. Random errors arising from problems such as limited instrument precision lead to uncertainty in final estimates of flux values and cannot be removed. While there are many sources of error and uncertainty in measurements of fluxes, we quantify here the uncertainty that random sampling errors of the isotopic composition of water vapor add to total uncertainty in the isotopic composition of surface to atmosphere water vapor flux.

Estimates of the uncertainties associated with each technique are calculated to preform an inter-comparison of methodologies. Both the Keeling plot and flux gradient methods rely on linear regression, for which error analysis and uncertainty estimators are well documented [Taylor, 1997]. The eddy covariance method is based on Reynolds algebra and statistical techniques used to assess flux uncertainty are associated with high computational requirements [Billesbach, 2010]. Additionally, many eddy covariance uncertainty estimators are vulnerable to contamination from systematic errors or rely on arbitrary parameter selection [Billesbach, 2010]. 
X - 16 GOOD, SODERBERG, WANG, \& CAYLOR: UNCERTAINTY IN MEASUREMENTS OF $\delta_{E T}$

Prior efforts have focused on the appropriate statistical regression techniques to use in isotope studies [Pataki et al., 2003; Zobitz et al., 2006; Saleska et al., 2006]. In all subsequent analyses we consider only random errors associated with the measurement of $\delta$ (or of rare isotope ${ }^{\alpha} \chi_{v}$ ) values in the ICOS system and assume errors in $\chi_{v}$ and wind speeds are negligible compared to that of the $\delta$ or ${ }^{\alpha} \chi_{v}$ [Zobitz et al., 2006]. Using both large datasets of observations and numerically simulated data, Zobitz et al. [2006] showed that ordinary least squares (Model I) regression, which considers only random errors in $\delta$ values, provides less biased estimates of flux end-members than geometric mean (Model II) regression. The increased bias in Model II regression, which considers random errors in both $\delta$ and $\chi_{v}$, is due to the relatively large variability in the independent variable $\left(\chi_{v}\right)$ when compared to smaller variability and higher signal to noise ratio of the dependent variable $(\delta)$ in the linear regression [Zobitz et al., 2006].

For ordinary least squares linear regression techniques, standard uncertainty analysis methods can be used. Given a set of $N$ data points $\left(x_{i}, y_{i} ; i=1,2, \ldots, N\right)$, and a linear model of the form $\hat{y}=A+B x_{i}$, uncertainty in the intercept $A$ and slope $B$ and are given by Taylor [1997]:

$$
\sigma_{A}=\epsilon \sqrt{\frac{\Sigma x^{2}}{N \Sigma x^{2}-(\Sigma x)^{2}}}
$$

and

$$
\sigma_{B}=\epsilon \sqrt{\frac{N}{N \Sigma x^{2}-(\Sigma x)^{2}}},
$$

where $\epsilon$ represents the standard deviation of random errors on measured values of $y$ with respect to the best linear model, $\hat{y}$, found with ordinary least squares regression. The 
GOOD, SODERBERG, WANG, \& CAYLOR: UNCERTAINTY IN MEASUREMENTS OF $\delta_{E T} \quad \mathrm{X}-17$

value $\epsilon$ is computed as [Taylor, 1997]:

$$
\epsilon=\sqrt{\frac{1}{N-2} \sum_{i=1}^{N}\left(y_{i}-A-B x_{i}\right)^{2}},
$$

and represents the standard deviation of model errors in the linear relationship between $y$ and $x$. Additionally, we have the statistical identities [Ross, 2007]:

$$
\Sigma x^{2}=(N-1) \sigma_{x}^{2}+N \bar{x}^{2} \text { and }(\Sigma x)^{2}=N^{2} \bar{x}^{2} .
$$

\subsection{Keeling plot $\delta_{E T}$ uncertainty:}

The accuracy of a Keeling plot in estimating surface vapor flux isotope composition is directly determined from the uncertainty associated with the regression intercept. This uncertainty was examined in detail by Pataki et al. [2003] for Keeling plots and Zobitz et al. [2006] for both Keeling plots and Miller-Tans plots, using both Model I and Model II regression techniques. In the case of least squares regression (Model I) where only random errors in the isotopic composition are considered, the relationships in equation (15) are utilized in equation (12). The uncertainty, $\sigma_{\delta_{E T}}(K P)[\%]$, of our estimated value of $\delta_{E T}$ from the Keeling plot is given by:

$$
\sigma_{\delta_{E T}}(K P)=\epsilon_{\delta} \sqrt{\frac{(N-1) \sigma_{\chi}^{2}+N \overline{\chi v}^{2}}{N(N-1) \sigma_{\chi}^{2}}} .
$$

The quantities $\bar{\chi}$ and $\sigma_{\chi}$ are the mean and standard deviation of the measured water vapor mixing ratio. The coefficient of variation, $c_{v} \equiv \sigma_{\chi} /\left|\overline{\chi_{v}}\right|[-]$, is used to express the normalized variability in the concentration of the measured water vapor mixing ratio. The $\epsilon_{\delta}[\% 0]$ term, calculated with equation (14), includes all instrument system noise and random 
X - 18 GOOD, SODERBERG, WANG, \& CAYLOR: UNCERTAINTY IN MEASUREMENTS OF $\delta_{E T}$

sampling error within the ICOS system with respect to $\delta$ notation. This key parameter represents the standard deviation from true values expected in a single measurement of the ICOS system at its sampling frequency given the current configuration. Uncertainty in the isotopic composition of evapotranspiraiton is then expressed as a function of the variability of water vapor in the atmosphere, configuration random sampling error, and sample count as:

$$
\sigma_{\delta_{E T}}(K P)=\epsilon_{\delta} \frac{1}{c_{v} \sqrt{N}} \sqrt{c_{v}^{2}+\frac{N}{N-1}} .
$$

\subsection{Flux gradient $\delta_{E T}$ uncertainty:}

Uncertainty in estimates of the $R_{E T}$ from the flux gradient method is calculated by estimating the uncertainty in the slope of the regression of ${ }^{\alpha} \chi_{v}$ against ${ }^{\beta} \chi_{v}$. Utilizing the identities of (15) with equation (13), the expected uncertainty in $R_{E T}$ can be expressed as a function of $\epsilon_{\alpha} \chi_{v}\left[\mathrm{~mol} \alpha \mathrm{mol}\right.$ dry $\left.\operatorname{air}^{-1}\right]$, where $\epsilon_{\alpha} \chi_{v}$ is defined as the expected standard deviation of measured values of ${ }^{\alpha} \chi_{v}$ with respect to the best linear relationship between ${ }^{\alpha} F_{E T}$ and ${ }^{\beta} F_{E T}$, given by equation (14). Measurement of the rare isotope $\alpha$ is inherently less precise than that of the abundant isotope $\beta$ [Zobitz et al., 2006], therefore we assume that all random errors in sampling within the system are contained within the $\epsilon_{\alpha} \chi_{v}$ term so that the best estimate of uncertainty in $R_{E T}$ is expressed as:

$$
\sigma_{R_{E T}}(F G)=\epsilon^{\alpha} \chi_{v} \sqrt{\frac{N}{N(N-1) \sigma_{\beta}^{2} \chi_{v}}},
$$

where $\overline{{ }^{\beta} \chi_{v}}$ is the mean and $\sigma_{\beta} \chi_{v}$ is the standard deviation of the molecular mixing ratio of the abundant water vapor isotope in the atmosphere at the measurement location. We define the expected uncertainty in measurements of the isotope ratio in delta notation as $\epsilon_{\delta}=\epsilon_{\alpha_{\chi_{v}}} /\left(R_{s t d}\left|\overline{{ }^{\beta} \chi_{v}}\right|\right)$ and approximate $\left|\overline{{ }^{\beta} \chi_{v}}\right| / \sigma_{\beta} \chi_{v}$ by $\left|\overline{\chi_{v}}\right| / \sigma_{\chi} \equiv c_{v}^{-1}$ in equation (18). 
For the flux gradient technique the configuration random sampling error is approximated as:

$$
\sigma_{\delta_{E T}}(F G)=\epsilon_{\delta} \frac{1}{c_{v} \sqrt{N}} \sqrt{\frac{N}{N-1}} .
$$

\subsection{Eddy covariance $\delta_{E T}$ uncertainty:}

The estimation of the covariance uncertainty, $\sigma_{\overline{w^{\prime} c^{\prime}}}$, (the standard deviation of the covariance of scalar $c$ with wind $w$ ) is statistically more complex relative to the simple linear regression estimates of the previous sections and few studies report uncertainties associated with flux measurements or simply estimate uncertainties as a constant fraction of the measurement [Billesbach, 2010]. Previous research into the uncertainty of eddy covariance measurements has been typically limited to comparison of the output of multiple co-located towers or comparison of multiple days of data [Hollinger and Richardson, 2005; Billesbach, 2010; Sturm et al., 2012]. The statistical technique developed by Mann and Lenschow [1994], which was originally derived from aircraft data, is based on the correlation coefficient between $w^{\prime}$ and the scalar quantity $c^{\prime}$. This method was developed to estimate the eddy covariance flux uncertainty without the use of co-located towers or time-shifted data. The Mann and Lenschow [1994] formulation for the uncertainty of an eddy covariance flux of scalar $c$ is:

$$
\sigma_{\overline{w^{\prime} c^{\prime}}}(M L)=\left|\overline{w^{\prime} c^{\prime}}\right| \sqrt{\frac{2 \tau_{f}}{N}} \sqrt{\frac{1+r_{w^{\prime} c^{\prime}}^{2}}{r_{w^{\prime} c^{\prime}}^{2}}},
$$
$\tau_{f}=z_{m} / \bar{u}$, when $z_{m}$ is the measurement height and $\bar{u}$ is the mean horizontal wind velocity, and $r_{w^{\prime} c^{\prime}}=\overline{w^{\prime} c^{\prime}} / \sigma_{w} \sigma_{c}$, is the correlation coefficient between the vertical wind speed and the scalar in question. Similarly, Finkelstein and Sims [2001] presented a technique based 
X - 20 GOOD, SODERBERG, WANG, \& CAYLOR: UNCERTAINTY IN MEASUREMENTS OF $\delta_{E T}$

on the auto-covariance and cross-covariance of both $w^{\prime}$ and $c^{\prime}$ such that

$$
\begin{aligned}
\sigma \overline{w^{\prime} c^{\prime}}(F S)= & \frac{1}{\sqrt{N}}\left(\sum_{p=-m}^{m} \hat{\gamma}_{w^{\prime}, w^{\prime}}(p) \hat{\gamma}_{c^{\prime}, c^{\prime}}(p)\right. \\
& \left.+\sum_{p=-m}^{m} \hat{\gamma}_{w^{\prime}, c^{\prime}}(p) \hat{\gamma}_{c^{\prime}, w^{\prime}}(p)\right)^{\frac{1}{2}}
\end{aligned}
$$

where $\hat{\gamma}_{x, x}(h)$ is the auto-covariance and $\hat{\gamma}_{x, y}(h)$ is the cross-covariance at a lag $h$. Both the techniques of Mann and Lenschow [1994] and Finkelstein and Sims [2001] have been shown to compare well with uncertainty estimates from co-located towers and time shifted data [Hollinger and Richardson, 2005; Billesbach, 2010]. These methods may be calculated directly for each 30-minute averaging block during flux tower operation.

Finally, if random errors, $\epsilon$, in scalar concentration fluctuations, $c^{\prime}$, are assumed to contribute the majority of uncertainty to flux estimates, it can be shown that the uncertainty of a covariance estimate is properly described by:

$$
\sigma_{\overline{w^{\prime} c^{\prime}}}(E P)=\epsilon_{c^{\prime}} \frac{\sigma_{w}}{\sqrt{N}}
$$

where $\sigma_{w}$ is the variance in vertical wind speed, and $\epsilon_{c}$ is standard deviation of the random error added to the scalar signal $c$. Equation (22) expresses the uncertainty of a covariance measurement with respect to expected random errors in a given instrument configuration and provides a useful tool for assessing the instrument precision required to satisfactorily compute an eddy covariance. A derivation of equation (22) is presented in Appendix A.

With this simple formulation, we can express the uncertainty in isoforcing covariance estimates with respect to $\epsilon_{\delta}$ with equation (22) and then propagate expected random errors through equation (11) to estimate the uncertainty in the isotopic composition of evapotranspiration calculated with the eddy covariance method following standard statistical random error propagation techniques [Taylor, 1997]. The expected uncertainty in 
GOOD, SODERBERG, WANG, \& CAYLOR: UNCERTAINTY IN MEASUREMENTS OF $\delta_{E T} \quad \mathrm{X}-21$

the isotopic composition of water vapor flux calculated with the eddy covariance method becomes

$$
\sigma_{\delta_{E T}}(E C)=\epsilon_{\delta}\left|\frac{\overline{\chi_{v}}}{\overline{w^{\prime} \chi_{v}^{\prime}}}\right| \frac{\sigma_{w}}{\sqrt{N}}+\frac{\sigma_{\delta_{v}}}{\sqrt{N}}
$$

where $\sigma_{\delta_{v}} / \sqrt{N}$ is the standard error of the mean for $\overline{\delta_{v}}$.

\section{Methodology}

\subsection{Equipment deployment and data collection}

In May 2011 a short field campaign was conducted to directly measure the isotopic composition of evapotranspiration using the Keeling plot, flux gradient, and eddy covariance methods and assess the uncertainties associated with each method. The experiment was conducted at the Mpala Research Center/Princeton University eddy-covariance tower. This installation is located in a semi-arid mixed savanna ecosystem that receives an annual rainfall of around $500 \mathrm{~mm}$, a large portion of which occurs in March, April and May [Franz et al., 2010]. The vegetation surrounding the tower has an average height of approximately 4 meters and consists of a sparse mixture of mainly Acacia woody species and $\mathrm{C}_{4}$ grasses. Constructed in 2010, the tower is a free-standing climb-up structure 24 meters tall located at the Mpala Research Center in Laikipia, Kenya $\left(0.4856^{\circ} \mathrm{N}, 36.8701^{\circ} \mathrm{E}\right.$, 1619 meters above mean sea level). The tower has been operational since February 2010, and is equipped with a sonic anemometer (CSAT-3, Campbell Scientific, Logan, UT) and an infrared gas analyzer (Li-7500, LiCor Biosciences, Lincoln, NB) positioned at $22.5 \mathrm{~m}$ above the ground surface (Figure 1). Sensors to measure short wave and long wave radiation, soil moisture, precipitation, relative humidity, air temperature, and a suite of other environmental parameters are also permanently installed at the site. 
X - 22 GOOD, SODERBERG, WANG, \& CAYLOR: UNCERTAINTY IN MEASUREMENTS OF $\delta_{E T}$

A key research objective of this installation is the long term study of surface fluxes of evapotranspiration with the goal of partitioning $F_{E T}$ into is constituent components. To this end, a water vapor isotope analyzer using off-axis integrated cavity output spectroscopy (ICOS1; DLT-100, Los Gatos Research Inc., Mountain View, CA) has been measuring the isotopic composition of atmospheric water vapor since February 2010. The ICOS1 intake is co-located with the CSAT-3 and Li-7500 at $22.5 \mathrm{~m}$ (Figure 1) and the ICOS1 itself is housed within a ventilated case in a fiberglass control shed located at the base of the tower. A three-chamber vacuum pump draws air at the rate of $500 \mathrm{~mL}$ per minute through a $1 / 4$ inch outer diameter (OD) teflon intake tube and into ICOS1. The Los Gatos ICOS systems contain a measurement cell $0.59 \mathrm{~m}$ long and $830 \mathrm{~mL}$ in volume that is maintained at a pressure of $\sim 52 \mathrm{hPa}$ and a temperature of $49^{\circ} \mathrm{C}$. These pressures, temperatures and flow rates correspond to a residence time, $\tau[\mathrm{s}]$, in the measurement cell of approximately 5.7 seconds in ICOS1. A near-infrared diode laser is tuned over selected absorption lines and directed off-axis into chamber, resulting in an absorption path length of several kilometers. Transmitted laster intensities are recored and combined with measured temperature and pressure in the cell to determine the isotopic composition within the cell at a maximum measurement rate of $2 \mathrm{~Hz}$ [Baer et al., 2002; Sturm and Knohl, 2010].

During the May 2011 campaign, a second ICOS system was installed on the tower (ICOS2; same model as ICOS1). ICOS2 was connected via 16m of 1/4" OD teflon tubing to an electronically controlled manifold with six teflon solenoid valves (255T091, NR Research Inc., West Caldwell, NJ). The same model pump as the pump on ICOS1 drew air sequentially from four intakes (approximately located at $22.5 \mathrm{~m}, 18 \mathrm{~m}, 13.5 \mathrm{~m}$, and 
GOOD, SODERBERG, WANG, \& CAYLOR: UNCERTAINTY IN MEASUREMENTS OF $\delta_{E T} \quad \mathrm{X}-23$

311

$9 \mathrm{~m}$ above ground level) routed via $12.5 \mathrm{~m}$ of $1 / 8$ " OD teflon tubing to the respective manifold inlet port (Figure 1). Air was drawn from each height for 7.5 minutes, allowing the system to cycle through all four heights every 30 minutes.

\subsection{Instrument calibration and data processing}

The calibrations of ICOS1 and ICOS2 were conducted before and after the May 2011 campaign using three liquid water isotope standards (Working Standards \#1, \#3 and \#5, Los Gatos Research Inc., WS1 WS3 \& WS5) that span $-154.1 \%$ o to $-9.8 \%$ for $\delta^{2} \mathrm{H}$ and $-19.57 \%$ to $-2.96 \%$ for $\delta^{18} \mathrm{O}$, well outside the measured range of ambient water vapor isotope values. Sample introduction was via a liquid water nebulizer (WVISS, Los Gatos Research Inc.) that provides a stream of water vapor of known isotope composition, with user control of the vapor concentration of this stream. During calibration runs data was recorded for 3 minutes after the WVISS vapor output stabilized. During typical operation ICOS1 is brought to the lab and calibrated approximately every two weeks. ICOS2 normally remains in the laboratory and is used for analysis of liquid water samples, with calibration runs for each day that samples are analyzed.

Routine lab calibrations of ICOS1 and ICOS2 using WS3 and WS5 result in long-term (October 2010 to September 2011) uncertainty estimates of $2.3 \%$ and $1.5 \%$ for $\delta^{2} \mathrm{H}$, and $0.4 \%$ and $0.5 \%$ for $\delta^{18} \mathrm{O}$ for $\operatorname{ICOS} 1(N=14)$ and ICOS2 $(N=36)$ respectively, when measuring WS3 at water vapor concentrations between 20,000 to 30,000 ppmv. For the May 2011 campaign, the concentration dependence of each ICOS was tested across a water vapor concentration range of 10,000 to 30,000 ppmv using all three standards. For the six month period bracketing the experiment (February to July 2011) the relationship between vapor mixing ratio and measurement errors was examined with the results shown 
X - 24 GOOD, SODERBERG, WANG, \& CAYLOR: UNCERTAINTY IN MEASUREMENTS OF $\delta_{E T}$

in Figure 3. A strong vapor dependence was observed in ICOS1 but not ICOS2, and is likely the result of firmware updates on the later model ICOS2. For quality control, in addition to the analyst's determination of run stability, calibration runs with a water vapor concentration greater than 20,000 ppmv were excluded if they exhibited a standard deviation of greater than $2.0 \%$ for $\delta^{2} \mathrm{H}$, and $0.4 \%$ for $\delta^{18} \mathrm{O}$. Correcting the calibration data using the concentration dependence gives an estimated uncertainty of $2.2 \%$ and $1.6 \%$ for $\delta^{2} \mathrm{H}$, and $0.6 \%$ and $0.7 \%$ for $\delta^{18} \mathrm{O}$ for $\operatorname{ICOS} 1(N=20)$ and ICOS2 $(N=77)$. During field deployment, ICOS1 and ICOS2 routinely sampled the same air at the same time for $25 \%$ of each 30 minute block. Good agreement between ICOS1 and ICOS2 during these periods (calibrated data) was observed for hydrogen, with $\delta^{2} \mathrm{H}_{\mathrm{ICOS} 1}=7.4+1.0 \times \delta^{2} \mathrm{H}_{\mathrm{ICOs} 2}\left(R^{2}=0.93\right)$ but considerably less agreement was found for oxygen, with $\delta^{18} \mathrm{O}_{\mathrm{Icos} 1}=0.15-8.18 \times \delta^{18} \mathrm{O}_{\mathrm{ICos} 2}$ $\left(R^{2}=0.01\right)$. The Li-7500 and both ICOS systems were independently calibrated for bulk water vapor concentration measurements using a dew point generator (Li-610, Li-Cor Biosciences, Lincoln, NE). The Los Gatos ICOS system reports isotope ratios, $\delta$ values, and bulk vapor concentration, from which individual isotopologue dry mixing ratios are calculated (see Appendix B for calculations). Power spectra analysis, as shown in Figure 4, reveals the expected $-5 / 3$ power law decay Kaimal and Finnigan [1994] in contributed variability for the open path water vapor measurements. Measurements of bulk water vapor from the closed path ICOS1 system demonstrate lost variance at frequencies greater than $0.03 \mathrm{~Hz}$ due to the slower dynamic frequency response of the ICOS system as well as path and tube averaging. In the case of the isotopic composition of water vapor, $\delta$ values for both ${ }^{2} \mathrm{H}$ and ${ }^{18} \mathrm{O}$ exhibit large variability at higher frequencies, likely due to short term random instrument drift on the order of 10 to 100 seconds. Increased noise in the 
GOOD, SODERBERG, WANG, \& CAYLOR: UNCERTAINTY IN MEASUREMENTS OF $\delta_{E T} \quad \mathrm{X}-25$

ICOS system $\delta$ measurements add significant variance at frequencies higher than $0.03 \mathrm{~Hz}$ for ${ }^{2} \mathrm{H}$ and 0.01 for ${ }^{18} \mathrm{O}$.

A quality control filter was used to select 30 minute averaging blocks of data for further analysis. For this study we chose to analyze 30-minute periods when the evapotranspiration flux was reliably observed, following a filtering scheme similar to Li and Bou-Zeid [2011]. All periods with $u^{*}$ values less than $0.01 \mathrm{~m} / \mathrm{s}$ and water vapor flux less then 0.5 mmol $\mathrm{m}^{-2} \mathrm{~s}^{-1}$ were excluded from further analysis. Additionally, periods with stable boundary layers, i.e., $z_{m} / L>0$ (see Kaimal and Finnigan [1994] for a definition of the Obukhov length scale $L)$ or non-stationary concentration levels were removed $(>50 \%$ covariance dispersion for 5min subintervals [Foken and Wichura, 1996]). Finally, only periods where the correlation between water vapor measurements within the ICOS systems and the Li-7500 were greater than 0.75 with lag times between 20 and 40 seconds were selected. These constraints resulted in 80 of the 288 available blocks being selected for further analysis, with 67 of these blocks occurring between 06:00hrs and 18:00hrs and 13 blocks occurring between 18:00hrs and 06:00hrs.

Post-processing of flux measurements included coordinate rotation of the wind speed matrix such that mean vertical and cross wind velocities are zero. Data spikes larger than four times the standard deviation of each 30-minute time series were removed. Both the water vapor and isotope measurements of ICOS1 and ICOS2 were temporally shifted using maximum correlation analysis between the ICOS vapor measurements and the Li7500 at top of the tower [Lee et al., 2004]. The lag correlation was calculated for each 30 minute averaging block independently for each ICOS, resulting in an average lag time of 30.1 seconds for ICOS1 and 33.1 seconds for ICOS2. These lag times are consistent with 
X - 26 GOOD, SODERBERG, WANG, \& CAYLOR: UNCERTAINTY IN MEASUREMENTS OF $\delta_{E T}$

the tube length and pump rates of the system configuration. The cospecta of the flux of bulk water vapor flux as well as the ${ }^{2} \mathrm{H}$ and ${ }^{18} \mathrm{O}$ isoforcings were calculated, and the average of all ten minute periods in selected time blocks is shown in Figure 5. Cospectra calculated from ICOS1 demonstrate flux attenuation relative to the open path system, with isoforcing exhibiting larger variability but similar trends as the closed path bulk vapor flux cospectra (5 right pannel, uncorrected).

Eddy covariance measurements of trace gasses made with slow response sensors, $1 / \tau \leq 2.5 \mathrm{~Hz}$, have demonstrated an ability to measure fluxes when proper consideration of co-spectral attenuation is compensated for and turbulent fluxes are large [Hendriks et al., 2008; Wohlfahrt et al., 2009; Detto et al., 2011]. Frequency response corrections, $H_{w^{\prime} c^{\prime}}(f)$, were applied to the co-spectra of the closed path and open path systems. For the open path calculations of $\overline{w^{\prime} \chi_{v}^{\prime}}$, block averaging, lateral separation, dynamic frequency response, scalar and vector path averaging, and digital filter corrections were applied [Moore, 1986; Lee et al., 2004]. For closed path calculations of $\overline{w^{\prime} \chi_{v}^{\prime}}, \overline{w^{\prime} \delta^{\prime}}\left({ }^{2} \mathrm{H}\right)$, and $\overline{w^{\prime} \delta^{\prime}}\left({ }^{18} \mathrm{O}\right)$, the above corrections as well as tube attenuation for laminar flow were applied [Lenschow and Raupach, 1991]. The frequency response correction factor, $C F_{w^{\prime} c^{\prime}}[]$, is the ratio of the corrected flux, $\overline{w^{\prime} c^{\prime}}$ corr , to the measured flux, $\overline{w^{\prime} c^{\prime}}$ mes. The correction factor is estimated with a transfer function $H_{w^{\prime} c^{\prime}}(f)$ as:

$$
C F_{w^{\prime} c^{\prime}}=\frac{\overline{w^{\prime} c^{\prime}} \text { corr }}{\overline{w^{\prime} c^{\prime}}}=\frac{\int_{0 e s}^{\infty} C o_{w^{\prime} c^{\prime}}(f) / H_{w^{\prime} c^{\prime}}(f) \mathrm{d} f}{\int_{0}^{\infty} C o_{w^{\prime} c^{\prime}}(f) \mathrm{d} f}
$$

where $C o_{w^{\prime} c^{\prime}}(f)$ is the co-spectra of vertical wind deviations $w^{\prime}$ and deviations scalar $c^{\prime}$ at frequency $f[\mathrm{~Hz}]$. Because all measurements are made of the same substance, bulk water vapor and its isotopologues, within the same ICOS cell, spectral similarity is assumed [Horst, 1997; Massman, 2000] between the normalized covariance of $\overline{w^{\prime} \chi_{v}^{\prime}}$ and $\overline{w^{\prime} \delta^{\prime}}$ such 
GOOD, SODERBERG, WANG, \& CAYLOR: UNCERTAINTY IN MEASUREMENTS OF $\delta_{E T} \quad \mathrm{X}-27$

that $C F_{w^{\prime} \chi_{v}^{\prime}}=C F_{w^{\prime} \delta^{\prime}}$. Due to the large variance of $\delta$ values at lower frequencies (Figure 4) we use the correction factor obtained from integration of the $w^{\prime} \chi_{v}^{\prime}(f)$ within ICOS1 for both $C F_{w^{\prime} \chi_{v}^{\prime}}$ and $C F_{w^{\prime} \delta^{\prime}}$. Closed path eddy covariance systems are susceptible to a kinetic fractionation effect due to a phase shift caused by differences in molecular diffusivities between isotopologues [Lenschow and Raupach, 1991; Massman, 1991; Griffis et al., 2008]. Given the tube length and pump rate of the closed path system, the transfer function for tube attenuation begins to decay around $0.2 \mathrm{~Hz}\left(H_{w^{\prime} \chi_{v}^{\prime}}(0.2 \mathrm{~Hz})=0.99\right)$, well beyond the ICOS residence frequency of $1 / \tau=0.17 \mathrm{~Hz}$. Thus kinetic effects occurring within the tube path occur below our system residence time and resulting phase shifts in isotopic composition are averaged out within the ICOS cell. This is further demonstrated by estimating the kinetic isotope fractionation factor, $\varepsilon_{k}[\%]$, with the integral of the average co-spectra of $w^{\prime} \chi_{v}^{\prime}$ from Figure 5 and the tube attenuation transfer function, Lenschow and Raupach [1991] equation 9, using the molecular diffusivities of ${ }^{1} \mathrm{H}_{2}^{16} \mathrm{O},{ }^{1} \mathrm{H}^{2} \mathrm{H}^{16} \mathrm{O}$, and ${ }^{1} \mathrm{H}_{2}^{18} \mathrm{O}$ [Merlivat, 1978]. The resulting kinetic fractionation factors given the observed average spectrum in the ICOS system are $0.007 \%$ and $0.0079 \%$ for hydrogen and oxygen respectively. After application of frequency response corrections, the integral flux from the ICOS system corresponds very well with that the open path setup (Figure 5, top left). The majority (66\%) of the flux lost in the closed path system is attributed to the 5.7 second response time of the ICOS systems, which is simply compensated for with a first order gain function [Moore, 1986], and is expected to affect bulk water vapor and isoforcing covariance estimates equally. After post-processing and quality control filtering we observe excellent matching between closed path and open path flux estimates of bulk water flux, with $F_{E T}^{\mathrm{Icos} 1}=-4.2 \times 10^{-6}+1.02 \times F_{E T}^{\mathrm{Liz} 500}\left(R^{2}=.97\right.$, bottom left panel Figure 5). 
X - 28 GOOD, SODERBERG, WANG, \& CAYLOR: UNCERTAINTY IN MEASUREMENTS OF $\delta_{E T}$

\subsection{Experimental configurations and calculations}

Seven different configurations of equipment and calculation methods were employed in this experiment. All measurements were taken above the canopy such that separate and potentially distinct isotope vapor sources on the surface are likely to be sufficiently mixed. Differences in surface source isotopic composition will, in the case of non well mixed conditions, lead to variability of $\delta_{E T}$ around a mean value. Three types of Keeling plots were used to estimate $\delta_{E T}$ and the uncertainty associated with it. The first Keeling plot method, $\mathrm{KP}_{22.5}$, used data from the ICOS with a single intake at $22.5 \mathrm{~m}$ (ICOS1). Each ICOS system records data at $1 \mathrm{~Hz}$ and a single 30 -minute averaging block contains $N=1800$ observations. The $\mathrm{KP}_{22.5}$ method utilized all 1800 data points to estimate the Keeling plot intercept. The second and third Keeling plot methods are calculated with data from the ICOS system with intakes at heights of 9, 14.5, 18 and 22.5 meters (ICOS2). The $\mathrm{KP}_{\overline{9}: \overline{22.5}}$ takes the last 5 minutes of data from each height and averages these values to produce four points along the profile of the tower $(N=4)$. This method approximates the signal that could be obtained from flask or cryogenic trapping methods (e.g [Helliker et al., 2002; Bowling et al., 2003]) where air is constantly collected and an average sample at each height is obtained. The average water vapor mixing ratio and average water vapor isotopic signature at the four heights is then used to calculate the Keeling plot intercept. The third Keeling plot method, $\mathrm{KP}_{9: 22.5}$ (i.e., Keeling plot, profile points), utilizes the last 5 minutes of data at each height from ICOS2 to calculate the Keeling plot intercept $(N=1200)$. For all three Keeling plot methods the intercept, $\delta_{E T}$ was determined using equation (3), and the uncertainty in the intercept value, $\sigma_{\delta}(K P)$, was found using equations (14) and (17). The average apparent standard deviation of 
GOOD, SODERBERG, WANG, \& CAYLOR: UNCERTAINTY IN MEASUREMENTS OF $\delta_{E T} \quad \mathrm{X}-29$

random errors, $\left\langle\epsilon_{\delta}\right\rangle$, was calculated by taking the average of all values obtained from equation (14) used to estimate uncertainties for each time block.

Two types of flux gradient calculations were made with the data from ICOS2. The $\mathrm{FG}_{\overline{9} \overline{2} \overline{22.5}}$ method uses the same height averaged values of isotope measurements as the $\mathrm{KP}_{\overline{9} \overline{22.5}}$ method to estimate the value of $R_{E T}$ and $\delta_{E T}$. Similarly, the $\mathrm{FG}_{9: 22.5}$ method utilizes all data collected during the last five minutes at each hight to estimate the value of $R_{E T}$. In both these methods the slope of ${ }^{\alpha} \chi_{v}$ versus ${ }^{\beta} \chi_{v}$ was determined using equation (6), and the uncertainty in the slope was found using equation (14) and (19). For the two flux gradient techniques, the value of $\left\langle\epsilon_{\delta}\right\rangle$ was estimated by as the average of the values of $\epsilon_{\alpha_{\chi_{v}}} /\left(R_{s t d}\left|\overline{\beta \chi_{v}}\right|\right)$ obtained from the each of the different time blocks. For both the $\mathrm{KP}_{\overline{9} \cdot \overline{22.5}}$ and $\mathrm{FG}_{\overline{9} \cdot \overline{22.5}}$ methods the regression of the $\sigma_{\delta}$ points against $c_{v}$ is governed by $\epsilon_{\bar{\delta}}$ not $\epsilon_{\delta}$, where $\epsilon_{\bar{\delta}}$ is the standard deviation of the mean apparent standard deviation of the particular method. To obtain the $\epsilon_{\delta}$ for the $\mathrm{KP}_{\overline{9}: \overline{22.5}}$ and $\mathrm{FG}_{\overline{9}: \overline{22.5}}$ methods, $\epsilon_{\bar{\delta}}$ is multiplied by the square root of the number of points in each of the 5 minute averages made at each height. This results in a value of $\epsilon_{\delta}$ for these two methods that represents the same underlying uncertainty as the $\epsilon_{\delta}$ calculated for the other methods.

Calculation of the isotopic composition of the vapor flux was also determined using the eddy covariance techniques. The bulk water surface evapotranspiration flux predicted with the open path Li7500 was in close agreement to $F_{E T}$ calculated with the water vapor measurements in the ICOS1 chamber, justifying our ability to estimate fluxes with the ICOS system. The high correlation between the two corrected measurements of $F_{E T}$ indicates that the lower frequency response of the closed path ICOS can be adequately resolved and corrected for in both bulk water vapor fluxes and isoforcing estimates. Spec- 
X - 30 GOOD, SODERBERG, WANG, \& CAYLOR: UNCERTAINTY IN MEASUREMENTS OF $\delta_{E T}$

tral analysis by Griffis et al. [2008, 2010] has also demonstrated that tube attenuation of the isotopologes of carbon dioxide and water vapor (with the possible exception of ${ }^{2} \mathrm{H}$ ) are likely negligible. Equation (11) was used to estimate $\delta_{E T}$ and both the methods of Mann and Lenschow [1994] $\left(\mathrm{EC}_{22.5}(\mathrm{ML})\right.$, equation 20) and Finkelstein and Sims [2001] $\left(\mathrm{EC}_{22.5}(\mathrm{FS})\right.$, equation 21) were used to estimate the uncertainty, $\sigma_{E T}(E C)$. For these two methods the value of $\left\langle\epsilon_{\delta}\right\rangle$ was found such that equations (20) and (21) most closely fit equation (22). Figure 6 demonstrates the fitting of $\left\langle\epsilon_{\delta}\right\rangle$ to both the ML and FS methods. The different combination of ICOS systems and computation methods as well as the average apparent standard deviation of random errors for each setup are summarized in Table 1. To demonstrate the different techniques used within this study to estimate $\delta_{E T}$, collected data, calculated $\delta_{E T}$, and, $\sigma_{\delta_{E T}}$ values for May 7th 2011 at 14:00-14:30hrs are provided in Figure 2.

\section{Results}

\subsection{Estimated flux composition}

The methods described in section 2 were used to calculate the isotopic composition of evapotranspiration from May 6th to May 11th 2011. For all methods the ability to predict $\delta_{E T}$ values improved during the day; $\delta_{E T}$ estimates were much more variable during the evening hours of low flux. Figure 7 shows the average diurnal cycle of $\delta_{E T}$ during the experiment for four of the methods, with all methods demonstrating larger variability from 16:00hrs to 8:00hrs, and larger agreement during the mid-day period from 8:00hrs to 16:00hrs. Furthermore, the Keeling plot method using the profile averaged values $\left(\mathrm{KP}_{\overline{9}: \overline{22.5}}\right)$ displays higher variably than the same methods when all points are used $\left(\mathrm{KP}_{9: 22.5}\right)$. The $\mathrm{KP}_{\overline{9}: \overline{22.5}}$ and $\mathrm{FG}_{\overline{9}: \overline{22.5}}$ methods and the $\mathrm{KP}_{9: 22.5}$ and $\mathrm{FG}_{9: 22.5}$ methods result 
GOOD, SODERBERG, WANG, \& CAYLOR: UNCERTAINTY IN MEASUREMENTS OF $\delta_{E T} \quad \mathrm{X}-31$

in identical diurnal cycles of $\delta_{E T}$, and are not shown in Figure 7 . The eddy covariance method also displays high variability and is at times out of phase with the other methods. Due to the relatively short measurement campaign, instrument failures, and variable conditions during different days the assessment of isotope flux methodologies from a purely diurnal averaging approach is limited. After quality control filtering we have 80 unique measurements of $\delta_{E T}$ and $\sigma_{\delta_{E T}}$ for each method. These measurements span three orders of magnitude for $c_{v}\left(10^{-3}\right.$ to $\left.10^{-1}\right)$ and five orders of magnitude for $\sigma_{\delta_{E T}}\left(10^{-1}\right.$ to $\left.10^{3}\right)$, and thereby provide an ample range of points for assessing the theoretical frameworks developed in sections 2 and 3.

The relationships between the estimated $\delta_{E T}$ values for each method were calculated and are given in Table 2. Overall, there is much higher agreement amongst methods using data from ICOS1 or amongst methods using data from ICOS2 them agreement between the two ICOS systems. Figure 8 shows a comparison between the $\delta_{E T}$ calculated using all the profile point data from ICOS2 with a Keeling plot $\left(\mathrm{KP}_{9: 22.5}\right)$ and other methods. The values calculated with the $\mathrm{KP}_{9: 22.5}$ and $\mathrm{FG}_{9: 22.5}$ are identical and fall on the 1:1 line (Root mean square error, RMSE $=1 \%$ and $0 \%$ ). Similarly, the values of $\mathrm{KP}_{\overline{9}: \overline{22.5}}$ and $\mathrm{FG}_{\overline{9}: \overline{22.5}}$ also are nearly identical (RMSE $=0 \%$ and $0 \%$ ), with a bias relative to the non average profile methods. The poor matching of $\delta$ values between ICOS1 and ICOS2 during periods of co-aligned sampling prohibits a thorough comparison of $\delta^{18} \mathrm{O}$ results. There is general agreement between the $\delta_{E T}$ values calculated between the methods $\mathrm{KP}_{9: 22.5}$, $\mathrm{KP}_{\overline{9}: \overline{22.5}}, \mathrm{FG}_{9: 22.5}$, and $\mathrm{FG}_{\overline{9}: \overline{22.5}}$ and general agreement between $\mathrm{KP}_{22.5}$ and $\mathrm{EC}_{22.5}$, as denoted by the trend lines of Figure 8 . 
X - 32 GOOD, SODERBERG, WANG, \& CAYLOR: UNCERTAINTY IN MEASUREMENTS OF $\delta_{E T}$

\subsection{Estimated methodological uncertainty}

In practice, the exact value of $\delta_{E T}$ is not known and we can only provide imperfect estimates of the true value and its associated uncertainties. A value of $\sigma_{\delta_{E T}}$ was calculated for each 30-minute time period in the filtered data set following the frameworks presented in section 3, with the results shown in Figure 9. The Keeling plot and flux gradient method uncertainties for both the ICOS2 profile points and ICOS1 data sets $\left(\mathrm{KP}_{9: 22.5}\right.$, $\mathrm{FG}_{9: 22.5}$, and $\mathrm{KP}_{22.5}$ ) are nearly identical, with only the $\mathrm{KP}_{22.5}$ for ${ }^{2} \mathrm{H}$ slightly lower. These uncertainties are significantly lower than all other methods, with typical values on the order of $\sim 10^{1} \%$ for hydrogen and $\sim 10^{0} \%$ for oxygen. The log uncertainly follows a very linear trend with the log of the coefficient of variation of water vapor. This linearity in log-log space is validated by the goodness of fit between equations (17), (19) and (23) solved using the average $\left\langle\epsilon_{\delta}\right\rangle$ values and the calculated uncertainty data, with the average uncertainty, $\left\langle\sigma_{\delta_{E T}}\right\rangle[\% 0]$, values given in Table 1 .

The average apparent standard deviation values, $\left\langle\epsilon_{\delta}\right\rangle$, represents the amount of random uncertainty inherent in a particular configuration and calculation scheme, with lower values identifying more precise methodologies for a given value of $c_{v}$. Therefore the low $\left\langle\epsilon_{\delta}\right\rangle$ values for the $\mathrm{KP}_{22.5}, \mathrm{KP}_{9: 22.5}$, and $\mathrm{FG}_{9: 22.5}$ methods of $2.20 \%$, $2.53 \%$, for hydrogen and $0.87 \%, 0.62 \%$, for oxygen respectively (see Table 1 ) represent the best configuration of equipment and post processing calculations of those assessed. Furthermore the similarity of these $\left\langle\epsilon_{\delta}\right\rangle$ estimates and the lab calibration values demonstrates the agreement between these methods and the expected instrument precision. Despite the similarity in $\sigma_{\delta_{E T}}$ values, the power law relationship obtained from the $\mathrm{KP}_{22.5}$ method is much tighter than that of the $\mathrm{KP}_{9: 22.5}$ and $\mathrm{FG}_{9: 22.5}$ methods, possibly due to the effects of switching between 
GOOD, SODERBERG, WANG, \& CAYLOR: UNCERTAINTY IN MEASUREMENTS OF $\delta_{E T} \quad \mathrm{X}-33$

manifold intake heights on ICOS2. However the range of $c_{v}$ values for this $\mathrm{KP}_{9: 22.5}$ and $\mathrm{FG}_{9: 22.5}$ is broader than those of $\mathrm{KP}_{22.5}$.

Both the Keeling plot and the flux gradient calculations made with the profile averaged values $\left(\mathrm{KP}_{\overline{9}: \overline{22.5}}\right.$ and $\left.\mathrm{FG}_{\overline{9}: \overline{22.5}}\right)$ result in uncertainties that are significantly larger than the same methods when all the data from the given time block is used as independent points. As noted by Pataki et al. [2003], decreasing the size of $N$ leads to increased uncertainty. These uncertainties an order of magnitude higher than those methods which use all of the 1 $\mathrm{Hz}$ data, with typical values on the order of $\sim 10^{2} \%$ for hydrogen and $\sim 10^{1} \%$ for oxygen. The change in $N$ from 1200 for the profile point data to $N=4$ for the profile averaged data results in a much smaller denominator in equations (17) and (19). Furthermore the linearity of the calculated uncertainty estimates with $c_{v}$ also decreases when data at each height are temporally averaged with much larger average uncertanties (Table 1). The apparent standard deviations values of the $\mathrm{KP}_{\overline{9}: \overline{22.5}}$, and $\mathrm{FG}_{\overline{9}: \overline{22.5}}$ configurations are $17.72 \%$ and $\mathbf{1 8 . 1 4 \% 0}$ for hydrogen and $5.83 \%$ and $5.89 \%$ for oxygen. These results demonstrate that there is a larger amount of uncertainty in methods that use averaged data for each height rather than those that use all the data points from each height independently.

The eddy covariance uncertainly estimates are also on the order of $\sim 10^{2} \%$ for hydrogen and $\sim 10^{1} \%$ for oxygen, comparable to the results from the profile averaged points. The $\left\langle\epsilon_{\delta}\right\rangle$ values in Table 1 represent the goodness of fit between equations (20) and (21) with equation (22). The statistical techniques of Mann and Lenschow [1994] and Finkelstein and Sims [2001] capture variability of $\sigma_{w^{\prime} \delta^{\prime}}$ across three orders of magnitude. All eddy covariance methods have average uncertainty values for $\left\langle\sigma_{\delta_{E T}}\right\rangle$ which are larger then those of the non-averaged Keeling and flux gradient methods. Figure 9 shows the calculated 
X - 34 GOOD, SODERBERG, WANG, \& CAYLOR: UNCERTAINTY IN MEASUREMENTS OF $\delta_{E T}$

\subsection{Uncertainty estimator approximations}

The development of measurement systems capable of recording isotopic compositions at high frequencies enables the collection of large sample counts during observation campaigns. This development allows for improved precision in the estimation of isotopic flux composition [Pataki et al., 2003]. Furthermore, high frequency measurements enable data 
GOOD, SODERBERG, WANG, \& CAYLOR: UNCERTAINTY IN MEASUREMENTS OF $\delta_{E T} \quad \mathrm{X}-35$ $r_{w^{\prime} \chi_{v}^{\prime}}$ as

Therefore, when $N$ is large, $c_{v}$ is small, and ${ }^{\beta} \chi_{v}\left|/ \sigma_{\chi^{\beta}} \approx\right| \overline{\chi_{v}} \mid / \sigma_{\chi}$, the uncertainty inherent in a calculation with the flux gradient method is the same as that of a calculation with the Keeling plot method. In the case of the eddy covariance technique, we wish to express equation (23) in similar terms as equation (25). Multiplying the the first term of (23) by $\sigma_{\chi} / \sigma_{\chi}$ allows us to rewrite this equation with respect to $c_{v}$ and the correlation coefficient

$$
\begin{aligned}
\sigma_{\delta_{E T}}(E C) & =\epsilon_{\delta} \frac{1}{c_{v} \sqrt{N}}\left(\frac{1}{\left|r_{w^{\prime} \chi_{v}^{\prime}}\right|}+\frac{c_{v} \sigma_{\delta_{v}}}{\epsilon_{\delta}}\right) \\
& \approx \epsilon_{\delta} \frac{1}{c_{v} \sqrt{N}}\left(\frac{1}{\left|r_{w^{\prime} \chi_{v}^{\prime}}\right|}\right) .
\end{aligned}
$$

Equation (26) may be obtained from either a derivation of $\delta_{E T}$ based on $\overline{w^{\prime \alpha} \chi_{v^{\prime}}} / \overline{w^{\prime \beta} \chi_{v^{\prime}}}$ or from isoflux covariance estimates, with the same final expression. Our results show here that uncertainty in eddy covariance estimates of flux isotopic composition can only approach that of the flux-gradient or Keeling plot when water vapor and vertical wind are perfectly correlated.

By combining equation (25) with (26) we see that ratio of uncertainty between the eddy covariance and Keeling plot methods, $\sigma_{\delta_{E T}}(E C) / \sigma_{\delta_{E T}}(K P)$, is proportional the reciprocal 
X - 36 GOOD, SODERBERG, WANG, \& CAYLOR: UNCERTAINTY IN MEASUREMENTS OF $\delta_{E T}$

of the correlation coefficient between vertical wind speed and water vapor, i.e.,

$$
\frac{\sigma_{\delta_{E T}}(E C)}{\sigma_{\delta_{E T}}(K P)}=\left\langle^{*} \epsilon_{\delta}\right\rangle \frac{1}{\left|r_{w^{\prime} \chi_{v}^{\prime}}\right|} \propto \frac{1}{\left|r_{w^{\prime} \chi_{v}^{\prime}}\right|} .
$$

Where $\left\langle{ }^{*} \epsilon_{\delta}\right\rangle=\left\langle\epsilon_{\delta}\right\rangle(E C) /\left\langle\epsilon_{\delta}\right\rangle(K P)$. Figure 11 depicts this ratio as a function of $r_{w^{\prime} \chi_{v}^{\prime}}$ for both hydrogen and oxygen isotopes. The line of $\left\langle{ }^{*} \epsilon_{\delta}\right\rangle /\left|r_{w^{\prime} \chi_{v}^{\prime}}\right|$ is also shown, and all $\sigma_{\delta_{E T}}(E C) / \sigma_{\delta_{E T}}(K P)$ values fall on or near this line.

The average apparent standard deviation values, $\left\langle\epsilon_{\delta}\right\rangle$, obtained from each of the methods are all approximatly greater than or equal to the calibrated instrument uncertainty (Table 1). Elevated values above calibration precision are attributable to the specific differences between the instrument configurations and calculations, however in the limit, the value of $\left\langle\epsilon_{\delta}\right\rangle$ will approach the inherent measurement system noise obtained from lab calibration. Given ideal sensor placement and configuration, the values $\left\langle\epsilon_{\delta}\right\rangle$ will be equal to instrument calibration, $\left\langle{ }^{*} \epsilon_{\delta}\right\rangle$ will be 1 , and the proportionality in equation (27) transforms into an equals sign. Because the eddy covariance technique invokes the relationship between isotope ratios and vertical wind speed, and also the relationship between vertical wind speed and water vapor concentration, the degradation of covariance between wind speed and water vapor results in larger uncertainties for covariance techniques when estimating isotope flux ratios.

\section{Discussion}

The results of this study provide useful guidance for optimizing the deployment of isotope monitoring equipment and the post-processing of isotope flux data. Though the data presented here consists of a relatively short field campaign, the analytical frameworks presented in section 3 are valid for any amount of data. The analysis and reporting of 
GOOD, SODERBERG, WANG, \& CAYLOR: UNCERTAINTY IN MEASUREMENTS OF $\delta_{E T} \quad \mathrm{X}-37$

uncertainty estimates for isotopic fluxes will be of increasing importance as isotopic techniques are integrated into standard ecological observation networks, such as the National Ecological Observation Network [Keller et al., 2008]. Additionally, the parameterization of land surface models using Bayesian frameworks and/or data assimilation schemes are improved if quantitative information about the uncertainty of isotopic flux measurements is reliably assessed [Ogée et al., 2004; Haverd et al., 2011].

We demonstrate that - during times of flux - methods utilizing all recorded isotope data as independent measurements outperform those methods where information is averaged for each height. The increased sample count and larger variability in water vapor observations, when 1800 data points instead of 4 are used to predict the slope and intercept of a regression line results in a large decrease in uncertainty, as demonstrated in Figure 9. Significant improvement in isotope flux ratio measurements is possible by the development of laser-based isotope analyzers over traditional cryogenic-based sampling methods. The high-frequency capabilities of laser-based isotope systems enables the measurement of isotopic composition at $\leq 1 \mathrm{~Hz}$, thereby generating enough information to considerably decrease the uncertainty of Keeling plots and flux gradient estimates as well as allowing for eddy-covariance measurements of isotopic fluxes of water vapor [Griffis et al., 2010]. This is a significant improvement in flux estimation over traditional cryogenic-based methods used by Keeling [1958] in the original development of his plotting technique or Yakir and Wang [1996] in application of time-averaged flux gradient techniques for isotopes.

At the 30-minute averaging timescale our calculated $\delta_{E T}$ and $\sigma_{\delta_{E T}}$ values for the Keeling plot and flux gradient methods were identical (Figure 8) when measured over the same vertical profile, as expected from the theory outlined in sections 2 and 3. These results 
X - 38 GOOD, SODERBERG, WANG, \& CAYLOR: UNCERTAINTY IN MEASUREMENTS OF $\delta_{E T}$

622

agree with early inter-comparisons of Griffis et al. [2004, 2005], however, later work by the same group [Griffis et al., 2007] found differences between the two methodologies in both absolute values and the uncertainties associated with these values. Griffis et al. [2007] claim that these discrepancies should be attributed to the differences between the footprint of a concentration measurement and the footprint of a flux measurement. While it has been clearly shown that the footprint of a mean scalar measurement is orders of magnitude larger than the footprint of flux measurement [Schmid, 1997, 2002; Kljun et al., 2002], it has also been shown that derived fluxes and flux-ratios calculated directly from scalar measurements do not have the same footprint as the scalars from which they are calculated [Horst, 1999; Stannard, 1997]. We believe that it is unjustified to assume that the footprint of $\delta_{E T}$ calculated from a vertical profile with a Keeling plot is the same as of footprint of $\delta_{v}$ simply because the Keeling plot only utilizes scalar measurements. If this argument were valid than the footprint of the flux gradient method should also be significantly larger then that of eddy covariance measurements, and this has been shown not to be the case [Horst, 1999].

Because the isotopic composition of the flux, expressed as $\delta_{E T}$ or $R_{E T}$, is a representation of the ratio of two fluxes, ${ }^{\alpha} F /{ }^{\beta} F$, a more direct analogy can be drawn with the Bowen ratio, which is the ratio of sensible heat flux to latent heat flux. Both Stannard [1997] and Horst [1999] have shown independently that when two fluxes satisfy scalar similarity then the footprint of the Bowen ratio is approximately equal to the footprint of eddy covariance or flux gradient measurements given that all are measured at the same average height. As both the Keeling plot and flux gradient methods are direct tools to assess a flux-ratio with the same base data $\left({ }^{\alpha} \chi_{v}\right.$ and $\left.{ }^{\beta} \chi_{v}\right)$, these two methods converge to the 
GOOD, SODERBERG, WANG, \& CAYLOR: UNCERTAINTY IN MEASUREMENTS OF $\delta_{E T} \quad \mathrm{X}-39$

same result when calculated over the same time averaging window and vertical profile, and therefore likely share the same footprint. A longer averaging window (e.g., 22:00 to 04:00 hrs local time in Griffis et al. [2007]) allows for non-stationarity in quantities such as eddy diffusivities [Kammer et al., 2011] to differentiate the signals obtained from the Keeling plot and flux gradient methods. Indeed, as noted by Zhang et al. [2006], at time intervals of 2 hrs or less, the Keeling plot and flux gradient methods show much higher agreement. Kammer et al. [2011] also observed very close $\left(R^{2}=.99\right)$ results between the two methods at short time intervals. However, when Keeling plots are calculated based on variations in time from measurements at a single elevation (i.e. the $\mathrm{KP}_{22.5}$ method) then the footprint will scale with mean wind velocity and have a significantly larger footprint. This mismatch in flux footprint area, as well as variations in $c_{v}$, are causes for the difference between the $\mathrm{KP}_{22.5}$ and $\mathrm{KP}_{9: 22.5}$ methods. The inter-method comparison of Santos et al. [In Press] also found high correlation between the Keeling plot and flux-gradient method, but differences were observed. In their study a Keeling plot was calculated based on data from a single height, while the flux-gradient estimate derived from two. Larger variability in concentrations observed from the multi-height measurements lead Santos et al. [In Press] to accept a much larger percentage of the estimates from the flux-gradient calculations and further demonstrates the improvements gained when analyzing variation due to vertical, as opposed to temporal, fluctuations.

Moisture advected into the measurement space or entrained from above the atmospheric boundary layer is not considered in the Keeling plot mixing model [Lee et al., 2011], and has been known to also affect flux gradient and eddy covariance calculations [Businger, 1986]. By conducting analysis at 30 minute blocks and only selecting periods of sta- 
X - 40 GOOD, SODERBERG, WANG, \& CAYLOR: UNCERTAINTY IN MEASUREMENTS OF $\delta_{E T}$

tionary conditions we minimize the influence of these sources of error. Based on the similarity of our calculated $\delta_{E T}$ values it is unlikely that entrainment of moisture into the boundary layer was significant. Additionally, the simplifications made in section 3.2 of $\epsilon_{R}=\epsilon_{\alpha_{v}} /\left|{\overline{\chi_{v}}}^{\beta}\right|$ and $\left|{\overline{\chi_{v}}}^{\beta}\right| / \sigma_{\beta} \chi_{v} \approx\left|\overline{\chi_{v}}\right| / \sigma_{\chi}$ may not hold for longer intervals when nonstationarity in surface conditions occurs, however, at short intervals these relationships are validated by the similarity of flux gradient and Keeling plot results. Our analyses demonstrate that at short time intervals there is essentially no difference between the flux-gradient and Keeling plot methods, given atmospheric entrainment is minor. Additionally, our study, though conducted over a mixed tree/grass savanna, consists of a uniform vegetation mixture for distance of $2-5$ kilometers in all directions. This consistent landscape, combined with a physically higher and larger vertical vapor sampling range that serves to average any spatial irregularities further diminishes in differences $\delta_{E T}$.

We report large values of uncertainty associated with eddy covariance estimates of surface flux isotope composition. The deployment for eddy covariance $\delta_{E T}$ measurements described here suffers from considerable limitations and is not the ideal configuration in many regards. Future deployment of a configuration consisting of a faster pump and shorter tube length will decease our co-spectral attenuation and likely improve performance. The long tube length and slow pump rate utilized in the system configuration result in a decrease in the turbulent information reaching our analyzer and is not the ideal setup for eddy covariance measurements of isofluxes. However, a majority of the turbulent flux $\left(\sim 1.5 \mathrm{mmol} \mathrm{m}^{-2} \mathrm{~s}^{-1}\right.$ out of $\left.\sim 2.2 \mathrm{mmol} \mathrm{m}^{-2} \mathrm{~s}^{-1}\right)$ is still present in the air stream when entering our measurement cell (Figure 5). Of the flux lost in our configuration, $66 \%$ is lost due to the 5.7 second residence time, with the remainder is distributed 
GOOD, SODERBERG, WANG, \& CAYLOR: UNCERTAINTY IN MEASUREMENTS OF $\delta_{E T} \quad \mathrm{X}-41$

between tube attenuation, path averaging and block averaging. The observed reduction of flux information is compensated for to the best of our ability with frequency response corrections [Moore, 1986; Lenschow and Raupach, 1991], resulting in corrected flux estimates with little bias or offset, $F_{E T}(\mathrm{ICOS})=-4.2 \times 10^{-6}+1.02 \times F_{E T}(\mathrm{Li7500})$, with $R^{2}=.97$. In our configuration, the sonic anemometer and intake location are placed at $22.5 \mathrm{~m}$ above a $4 \mathrm{~m}$ canopy and we have filtered out periods of atmospheric stability and low friction velocities, thus we expect and observe spectral (strong $-5 / 3$ power law decay Figure 4) and co-spectral shapes to conform to the theoretical shapes used in formulation of the frequency response corrections. However, as shown in figure 10, proper estimation of uncertainties in $\delta_{E T}$ allows for filtering out data points which we know to be unreliable. In the event that an ideal eddy covariance system did exist, uncertainties in $\delta_{E T}$ will remain proportional to $1 / r_{w^{\prime} \chi_{v}^{\prime}}$, and the apparent system error $\epsilon_{\delta}$ will not approach the inherent instrument precision. We therefore argue that this poor performance is to be expected from the eddy covariance techniques, even with ideal configurations, when they are used to estimate isotope flux ratios. Our conclusion is based on the examination of equations (25) and (26). Experimental research has demonstrated that during unstable boundary layer conditions the correlation between scalar fluxes and momentum flux degrades [Li and Bou-Zeid, 2011]. Because $\epsilon_{\delta}$ is present in both equations (25) and (26), further improvement in instrument performance will not increase the ability of eddy covariance systems to measure isotope fluxes relative to the Keeling plot or flux gradient method. The similar recent results of Sturm et al. [2012] also suggest that improvements in the instrument performance will only lead to limited improvement in isotopic flux estimates due to inherent uncertainty in eddy covariance methodology. Furthermore Sturm 
X - 42 GOOD, SODERBERG, WANG, \& CAYLOR: UNCERTAINTY IN MEASUREMENTS OF $\delta_{E T}$

et al. [2012] also conclude, and we agree, that a critical re-evaluation of isotopic equipment deployment and estimation techniques is required.

Our derived expressions for the uncertainty of isotopic composition of surface fluxes were all formulated with respect to instrument precision, $\epsilon_{\delta}$, and atmospheric water vapor variability, $c_{v}$. Given that $\epsilon_{\delta}$ and sample count $N$ are determined by the device used to perform the isotope analysis, the preferred physical configuration for vapor collection is typically the one which maximizes the range of vapor sample concentrations [Pataki et al., 2003; Kayler et al., 2010; Zobitz et al., 2006]. While the range of observed concentrations is highly correlated to the coefficient of variation observed (e.g $r_{c_{v}, \text { range }} \sim .91$ for ICOS1), the $c_{v}$ is directly related to $\delta_{E T}$ uncertainty through statistical functions developed in sections 2 and 3, and represents a more universal independent reference metric. Figure 12 provides the calculated values of $c_{v}$ as a function of measurement height normalized by the Obukhov length $(z / L)$. For a given set of atmospheric conditions, increasing height is associated with increasing $c_{v}$ values and thus improved estimates of $\delta_{E T}$. However, as is evident in the non-linear trend functions fit to the data, increasingly large changes in $z$ are needed to obtain improvements in $c_{v}$. Also evident is the fact that the $c_{v}$ values calculated from the ICOS2 data, which included air samples from a profile of measurements, are larger than those calculated with the ICOS1 data, which were recorded at a single point. Thus the sampling profile of instrument configurations should be installed across a wide range of heights so as to maximize the vapor concentration sampling range of isotope samples. Over the course of 18 months of tower vapor concentration measurements, our raw $\delta_{v}$ values span a range of $\sim 80 \%$ for hydrogen isotopes and $\sim 14 \%$ for oxygen isotopes. This broad range necessitates a likely cutoff threshold for our system of $c_{v}$ of approximately 0.005 , if 
GOOD, SODERBERG, WANG, \& CAYLOR: UNCERTAINTY IN MEASUREMENTS OF $\delta_{E T} \quad \mathrm{X}-43$

maximum uncertainties of $\sim 10 \%$ for hydrogen isotopes and $\sim 4 \%$ for oxygen isotopes are desired for $\delta_{E T}$ estimates to be within the limits of meaningful variations.

\section{Conclusion}

We have reported measurements and associated uncertainties for the isotope ratios of hydrogen and oxygen in water vapor surface fluxes. These measurements were made using both vapor profiling techniques and eddy covariance measurements with off axis integrated cavity output spectroscopy. This study is the first to report eddy covariance of isotope ratios of water vapor calculated with off axis ICOS systems, as well as the first to preform a detailed study of the uncertainties inherent in these measurements. We have presented expressions for the expected uncertainty of $\delta_{E T}$ measurements based on the Keeling plot, flux gradient, and eddy covariance methods. These uncertainty estimators are expressed in terms of the inherent system precision, $\epsilon_{\delta}$, and sampling frequency, $N$, of the instrument used, as well as the variability of water vapor concentration, $c_{v}$, observed during the measurement period.

We conclude that measurements made utilizing the high frequency capabilities of laserbased isotope analyzers allow for improvement over traditional flask trapping techniques where average samples are collected during intervals. This improvement is due to the larger variability in vapor measurements observed as well as improved statistical resolution due to larger sample counts. We find that results and associated uncertainties calculated from the Keeling plot and flux gradient methods are nearly identical during short periods, as expected from the derived uncertainty estimators. Additionally, we demonstrate that the uncertainty of flux ratio estimates calculated with the eddy covariance method are significantly larger than those estimated from the Keeling plot or flux gradient techniques. This 
X - 44 GOOD, SODERBERG, WANG, \& CAYLOR: UNCERTAINTY IN MEASUREMENTS OF $\delta_{E T}$

degradation in methodological precision is attributed to the loss of information inherent when relating one isotope to another via a third component to the calculations, vertical wind fluctuations. The loss of precision is found to be proportional to the inverse of the correlation coefficient between $w^{\prime}$ and $\chi_{v}^{\prime}$. Finally, we examine the consequence of sample deployment configuration on the observer range of water vapor measurements. We show that sampling schemes drawing vapor from a wider range variety of heights leads to more precise estimates of $\delta_{E T}$. The results of this study provide a framework for assessing and optimizing the estimation of isotopic ratios in surface fluxes.

In summary, we have outlined techniques to assess the precision of estimates of surface vapor flux isotope composition. When choosing between implementation methods, we urge the practitioner to exercise caution, and to consider not only the precision of a given methodology, but also the associated assumptions influencing its accuracy. Furthermore, the presented techniques are developed with the isotopic flux-ratio, $\delta_{E T}$ or $R_{E T}$, in mind, and if estimation of individual isotope fluxes, isoforcing, or isoflux is desired, different metrics of uncertainty must be developed. While the two part mixing model of the Keeling plot is the most straightforward, the consequences of non-stationary conditions as well as sensitivity to variability in source heterogeneity weaken the predictive power of this method. In the case of the flux gradient technique, the difficulty of resolving gradients as well as sampling constraints should be considered during implementation and deployment. However, many of the classical drawbacks inherent in the flux-gradient method do not factor into this technique because of cancelations which occur when taking the ratio of the two fluxes of nearly identical constituents observed at the same heights. The eddy covariance technique has been demonstrated as the most reliable method for 
GOOD, SODERBERG, WANG, \& CAYLOR: UNCERTAINTY IN MEASUREMENTS OF $\delta_{E T} \quad \mathrm{X}-45$

assessing the fluxes of water, carbon, and energy from the surface, but its application to isotope research should be applied with caution. As the total surface flux of water decreases (proportional to $r_{w^{\prime}} \chi_{v}^{\prime}$ ), the ability of this technique to resolve the relationship between the flux of the light and heavy isotopologues diminishes rapidly.

Acknowledgments. Stephen P. Good, Keir Soderberg, Lixin Wang, and Kelly Caylor acknowledge the National Science Foundation for financial support of this work (NSF Career Award EAR-0847368). Lixin Wang also acknowledges the financial support from Vice-Chancellor's postdoctoral research fellowship of University of New South Wales.

\section{References}

Baer, D., J. Paul, M. Gupta, and A. OKeefe (2002). Sensitive absorption measurements in the near-infrared region using off-axis integrated-cavity-output-spectroscopy. Applied Physics B: Lasers and Optics, 75(2):261-265.

Baldocchi, D. (2003). Assessing the eddy covariance technique for evaluating carbon dioxide exchange rates of ecosystems: past, present and future. Global Change Biology, 9(4):479-492.

Barbour, M., J. Hunt, N. Kodama, J. Laubach, T. McSeveny, G. Rogers, G., Tcherkez, and L. Wingate, L. (2011). Rapid changes in $\delta^{13} \mathrm{C}$ of ecosystem-respired $\mathrm{CO}_{2}$ after sunset are consistent with transient ${ }^{13} \mathrm{C}$ enrichment of leaf respired $\mathrm{CO}_{2}$. New Phytologist.

Billesbach, D. P. (2010). Estimating uncertainties in individual eddy covariance flux measurements: A comparison of methods and a proposed new method. Agricultural and Forest Meteorology, 151(3):394-405. 
X - 46 GOOD, SODERBERG, WANG, \& CAYLOR: UNCERTAINTY IN MEASUREMENTS OF $\delta_{E T}$

Bowling, D., D. Baldocchi, and R. Monson (1999). Dynamics of isotopic exchange of carbon dioxide in a Tennessee deciduous forest. Global Biogeochemical Cycles, 13(4):903922.

Bowling, D., D. Pataki, and J. Ehleringer (2003). Critical evaluation of micrometeorological methods for measuring ecosystem-atmosphere isotopic exchange of $\mathrm{CO}_{2}$. Agricultural and Forest Meteorology, 116(3-4):159-179.

Brunel, J., H. Simpson, A. Herczeg, R. Whitehead, and G. Walker (1992). Stable isotope composition of water vapor as an indicator of transpiration fluxes from rice crops. Water Resources Research, 28(5):1407-1416.

Businger, J., J. Wyngaard, Y Izumi, and E. Bradley (1971). Flux-profile relationships in the atmospheric surface layer. Journal of Atmospheric Sciences, 28(2):181-189.

Businger, J. (1986). Evaluation of the accuracy with which dry deposition can be measured with current micrometeorological techniques. Journal of Climate and Applied Meterology, 25:1100-1124.

Coplen, T. (2011). Guidelines and recommended terms for expression of stable-isotoperatio and gas-ratio measurement results. Rapid Communications in Mass Spectrometry, $25(17): 2538-2560$.

Craig, H. and L. Gordon (1965). Deuterium and oxygen-18 variations in the ocean and the marine atmosphere. In Tongiori, E., editor, Stable Isotopes Stable Isotopes in Oceanographic Studes and Paleotemperatures. Consiglio Nazionale Delle Richerche Laboratorio Di Gelogica Nucleare, Pisa, Italy.

De Laeter, J., J. Böhlke, P. De Bièvre, H. Hidaka, H. Peiser, K. Rosman, and P. Taylor (2003). Atomic weights of the elements: Review 2000. Pure and Applied Chemsitry, 
GOOD, SODERBERG, WANG, \& CAYLOR: UNCERTAINTY IN MEASUREMENTS OF $\delta_{E T} \quad \mathrm{X}-47$

825 75(6):683-800.

Detto, M., J. Verfaillie, F. Anderson, L. Xu, and D. Baldocchi, D. (2011). Comparing laser-based open-and closed-path gas analyzers to measure methane fluxes using the eddy covariance method. Agricultural and Forest Meteorology, 151(10):1312-1324.

Drewitt, G., C. Wagner-Riddle, and J. Warland (2009). Isotopic $\mathrm{CO}_{2}$ measurements of soil respiration over conventional and no-till plots in fall and spring. Agricultural and Forest Meteorology, 149(3-4):614-622.

Farquhar, G. and L. Cernusak (2005). On the isotopic composition of leaf water in the non-steady state. Functional Plant Biology, 32(4):293-303.

Farquhar, G. D., L. A. Cernusak, and B. Barnes (2007). Heavy water fractionation during transpiration. Plant Physiology, 143(1):11-18.

Finkelstein, P. L. and P. F. Sims (2001). Sampling error in eddy correlation flux measurements. Journal of Geophysical Research, 106(D4):3503-3509.

Foken, T. and B. Wichura (1996). Tools for quality assessment of surface-based flux measurements. Agricultural and Forest Meteorology, 78(1-2):83-105.

Franz, T., Caylor, K., Nordbotten, J., Rodríguez-Iturbe, I., and Celia, M. (2010). An ecohydrological approach to predicting regional woody species distribution patterns in dryland ecosystems. Advances in Water Resources, 33(2):215-230.

Gibson, J., Edwards, T., Bursey, G., and Prowse, T. (1993). Estimating evaporation using stable isotopes: quantitative results and sensitivity analysis for two catchments in northern canada, 24. Nordic Hydrology, 24(2-3):79-94.

Goodman, L. (1962). The variance of the product of K random variables. Journal of the American Statistical Association, 57(297):54-60. 
X - 48 GOOD, SODERBERG, WANG, \& CAYLOR: UNCERTAINTY IN MEASUREMENTS OF $\delta_{E T}$

Griffis, T., Baker, J., Sargent, S., Tanner, B., and Zhang, J. (2004). Measuring field-scale isotopic $\mathrm{CO}_{2}$ fluxes with tunable diode laser absorption spectroscopy and micrometeorological techniques. Agricultural and Forest Meteorology, 124(1-2):15-29.

Griffis, T., Lee, X., Baker, J., Sargent, S., and King, J. (2005). Feasibility of quantifying ecosystem-atmosphere $\mathrm{C}^{18} \mathrm{O}^{16} \mathrm{O}$ exchange using laser spectroscopy and the flux-gradient method. Agricultural and Forest Meteorology, 135(1-4):44-60.

Griffis, T., J. Zhang, J. Baker, N. Kljun, and K. Billmark (2007). Determining carbon isotope signatures from micrometeorological measurements: Implications for studying biosphere-atmosphere exchange processes. Boundary-Layer Meteorology, 123(2):295316.

Griffis, T., S. Sargent, J. Baker, X. Lee, B. Tanner, J. Greene, E. Swiatek, and K. Billmark (2008). Direct measurement of biosphere-atmosphere isotopic $\mathrm{CO}_{2}$ exchange using the eddy covariance technique. Journal of Geophysical Research, 113(D08304):1-20.

Griffis, T., S. Sargent, X. Lee, J. Baker, J. Greene, M. Erickson, X. Zhang, K. Billmark, N. Schultz, W. Xiao, and N. Hu. (2010). Determining the oxygen isotope composition of evapotranspiration using eddy covariance. Boundary-Layer Meteorology, 137(2):307326.

Griffis, T., X. Lee, X., Baker, J., Billmark, K., Schultz, N., Erickson, M., Zhang, X., Fassbinder, J., Xiao, W., and Hu, N. (2011). Oxygen isotope composition of evapotranspiration and its relation to $\mathrm{C}_{4}$ photosynthetic discrimination. Journal of Geophysical Research, 116(G01035):1-21.

Gu, L., W. Massman, R. Leuning, S. Pallardy, T. Meyers, P. Hanson, J. Riggs, K. Hosman, and B. Yang (2012). The fundamental equation of eddy covariance and its application 
GOOD, SODERBERG, WANG, \& CAYLOR: UNCERTAINTY IN MEASUREMENTS OF $\delta_{E T} \quad \mathrm{X}-49$

in flux measurements. Agricultural and Forest Meteorology, 152:135-148.

Guenther, A., W. Baugh, K. Davis, G. Hampton, P. Harley, L. Klinger, L., Vierling, P. Zimmerman, E. Allwine, S. Dilts, B. Lamb, H. Westberg, D. Baldocchi, C. Geron and T. Pierce (1996). Isoprene fluxes measured by enclosure, relaxed eddy accumulation, surface layer gradient, mixed layer gradient, and mixed layer mass balance techniques. Journal of Geophysical Research, 101(D13):18555-18567.

Gupta, P., D. Noone, D., J. Galewsky, C. Sweeney, and B. Vaughn (2009). Demonstration of high-precision continuous measurements of water vapor isotopologues in laboratory and remote field deployments using wavelength-scanned cavity ring-down spectroscopy (ws-crds) technology. Rapid Communications in Mass Spectrometry, 23(16):2534-2542.

Haverd, V., M. Cuntz, D. Griffith, C. Keitel, C. Tadros, and J. Twining (2011). Measured deuterium in water vapour concentration does not improve the constraint on the partitioning of evapotranspiration in a tall forest canopy, as estimated using a soil vegetation atmosphere transfer model. Agricultural and Forest Meteorology, 151(6):645-654.

Hoffmann, G., M. Cuntz, C. Weber, P Ciais, P. Friedlingstein, M. Heimann, J. Jouzel, J., Kaduk, E. Maier-Reimer, U. Seibt, U., and K. Six (2004). A model of the earths dole effect. Global Biogeochemical Cycles, 18(GB1008):1-15.

Hollinger, D. and A. Richardson (2005). Uncertainty in eddy covariance measurements and its application to physiological models. Tree Physiology, 25(7):873-885.

Horst, T. (1997). A simple formula for attenuation of eddy fluxes measured with firstorder-response scalar sensors. Boundary-Layer Meteorology, 82(2):219-233.

Horst, T. (1999). The footprint for estimation of atmosphere-surface exchange fluxes by profile techniques. Boundary-Layer Meteorology, 90(2):171-188. 
X - 50 GOOD, SODERBERG, WANG, \& CAYLOR: UNCERTAINTY IN MEASUREMENTS OF $\delta_{E T}$

Hendriks, D, A. Dolman, M. Van Der Molen, J. Van Huissteden, et al. (2008) A compact and stable eddy covariance set-up for methane measurements using off-axis integrated cavity output spectroscopy Atmospheric chemistry and Physics, 8(2):431-443.

Helliker, B., J. Roden, C. Cook, C., and J. Ehleringer (2002). A rapid and precise method for sampling and determining the oxygen isotope ratio of atmospheric water vapor. Rapid Communications in Mass Spectrometry, 16(10):929-932.

Kammer, A., B. Tuzson, L. Emmenegger, A. Knohl, J. Mohn, and F. Hagedorn (2011). Application of a quantum cascade laser-based spectrometer in a closed chamber system for real-time $\delta^{13} \mathrm{C}$ and $\delta^{18} \mathrm{O}$ measurements of soil-respired $\mathrm{CO}_{2}$. Agricultural and Forest Meteorology, 151(1):39-48.

Kayler, Z., L. Ganio, M. Hauck, T. Pypker, E. Sulzman, A. Mix, and B. Bond, B. (2010). Bias and uncertainty of $\delta^{13} \mathrm{CO}_{2}$ isotopic mixing models. Oecologia, 163(1):227-234.

Keeling, C. (1958). The concentration and isotopic abundances of atmospheric carbon dioxide in rural areas. Geochimica et Cosmochimica Acta, 13(4):322-334.

Keller, M., D. Schimel, W. Hargrove, and F. Hoffman (2008). A continental strategy for the National Ecological Observatory Network. Frontiers in Ecology and the Environment, 6(5):282-284.

Kaimal, J. and J. Finnigan (1994). Atmospheric boundary layer flows: their structure and measurement. Oxford University Press, USA.

Kljun, N., M. Rotach, and H. Schmid (2002). A three-dimensional backward lagrangian footprint model for a wide range of boundary-layer stratifications. Boundary-Layer Meteorology, 103(2):205-226. 
GOOD, SODERBERG, WANG, \& CAYLOR: UNCERTAINTY IN MEASUREMENTS OF $\delta_{E T} \quad \mathrm{X}-51$

Kroon, P., A. Hensen, H. Jonker, H. Ouwersloot, A. Vermeulen, and F. Bosveld, F. (2010). Uncertainties in eddy covariance flux measurements assessed from $\mathrm{CH}_{4}$ and $\mathrm{N}_{2} \mathrm{O}$ observations. Agricultural and Forest Meteorology, 150(6):806-816.

Lee, X., W. Massman, and B. Law, editors (2004). Handbook of Micrometrology, volume 29 of Atmospheric And Oceanographic Sciences Library. Kluwer Academic Publishers, New York.

Lee, X., R. Smith, and J. Williams (2006). Water vapour ${ }^{18} \mathrm{O} /{ }^{16} \mathrm{O}$ isotope ratio in surface air in New England, USA. Tellus B, 58(4):293-304.

Lee, X., T. Griffis, J. Baker, K. Billmark, K. Kim, and L. Welp (2009). Canopy-scale kinetic fractionation of atmospheric carbon dioxide and water vapor isotopes. Global Biogeochemical Cycles, 23(GB1002):1-15.

Lee, X., J. Huang, and E. Patton (2011). A large-eddy simulation study of water vapour and carbon dioxide isotopes in the atmospheric boundary layer. Boundary-Layer Meteorology, pages 1-20.

Lenschow, D. and Raupach, M. (1991). The attenuation of fluctuations in scalar concentrations through sampling tubes. Journal of Geophysical Research, 96(D8):15259-15.

Li, D. and E. Bou-Zeid (2011). Coherent structures and the dissimilarity of turbulent transport of momentum and scalars in the unstable atmospheric surface layer. Boundary-Layer Meteorology, 140(2):243-262.

Mann, J. and D. Lenschow. (1994). Errors in airborne flux measurements. Journal of Geophysical Research, 99(D7):14519-14526.

Massman, W. (1991). The attenuation of concentration fluctuations in turbulent flow through a tube. Journal of Geophysical Research, 96(D8):15269-15. 
X - 52 GOOD, SODERBERG, WANG, \& CAYLOR: UNCERTAINTY IN MEASUREMENTS OF $\delta_{E T}$

Massman, W. (2000). A simple method for estimating frequency response corrections for eddy covariance systems. Agricultural and Forest Meteorology, 104(3):185-198.

Merlivat, L. (1978). Molecular diffusivities of $\mathrm{H}_{2}^{16} \mathrm{O}, \mathrm{HD}^{16} \mathrm{O}$, and $\mathrm{H}_{2}^{18} \mathrm{O}$ in gases. The Journal of Chemical Physics, 69:2864.

Miller, M. (2002). Isotopic fractionation and the quantification of ${ }^{17} \mathrm{O}$ anomalies in the oxygen three-isotope system: an appraisal and geochemical significance. Geochimica et Cosmochimica Acta, 66(11):1881-1889.

Monin, A. and A. Obukhov (1954). Basic laws of turbulent mixing in the surface layer of the atmosphere. Contrib. Geophys. Inst. Acad. Sci., USSR,(151), pages 163-187.

Moore, C. (1986). Frequency response corrections for eddy correlation systems. BoundaryLayer Meteorology, 37(1):17-35.

Nickerson, N. and D. Risk (2009) Keeling plots are non-linear in non-steady state diffusive environments. Geophysical Research Letters, 36(L08401).

Ogée, J., P. Peylin, M. Cuntz, T. Bariac, Y. Brunet, P. Berbigier, P. Richard, and P. Ciais (2004). Partitioning net ecosystem carbon exchange into net assimilation and respiration with canopy-scale isotopic measurements: An error propagation analysis with ${ }^{13} \mathrm{CO}_{2}$ and $\mathrm{CO}^{18} \mathrm{O}$ data. Global Biogeochemical Cycles, 18(GB2019):1-16.

Ogée, J., M. Cuntz, P. Peylin, and T. Bariac (2007). Non-steady-state, non-uniform transpiration rate and leaf anatomy effects on the progressive stable isotope enrichment of leaf water along monocot leaves. Plant, Cell, and Environment, 30(4):367-387.

Pataki, D., J. Ehleringer, L. Flanagan, D. Yakir, D. Bowling, C. Still, N. Buchmann, J. Kaplan, and J. Berry (2003). The application and interpretation of Keeling plots in terrestrial carbon cycle research. Global Biogeochemical Cycles, 17(1):1-14. 
GOOD, SODERBERG, WANG, \& CAYLOR: UNCERTAINTY IN MEASUREMENTS OF $\delta_{E T} \quad \mathrm{X}-53$

Richardson, A., D. Hollinger, G. Burba, K. Davis, L. Flanagan, G. Katul, J. William Munger, D. Ricciuto, P. Stoy, A. Suyker, A., et al. (2006). A multi-site analysis of random error in tower-based measurements of carbon and energy fluxes. Agricultural and Forest Meteorology, 136(1):1-18.

Risi, C., S. Bony, F. Vimeux, C. Frankenberg, D. Noone, D., and J. Worden (2010). Understanding the sahelian water budget through the isotopic composition of water vapor and precipitation. Journal of Geophysical Research, 115(D24110):1-23.

Ross, S. M. (2007). Introduction to probability models. Academic Press, New York, 9th edition.

Saleska, S., J. Shorter, S. Herndon, R. Jiménez, J. McManus, J. Munger D. Nelson, and M. Zahniser (2006). What are the instrumentation requirements for measuring the isotopic composition of net ecosystem exchange of $\mathrm{CO}_{2}$ using eddy covariance methods? Isotopes in Environmental and Health Studies, 42(2):115-133.

E. Santos, C. Wagner-Riddle, X. Lee, J. Warland, S. Brown, R. Staebler, P. Bartlett, and K. Kim (In Press) Use of the isotope flux ratio approach to investigate the $\mathrm{C}^{18} \mathrm{O}^{16} \mathrm{O}$ exchange near the floor of a temperate deciduous forest Biogeosciences,

Schmid, H. (1997). Experimental design for flux measurements: matching scales of observations and fluxes. Agricultural and Forest Meteorology, 87(2-3):179-200.

Schmid, H. (2002). Footprint modeling for vegetation atmosphere exchange studies: a review and perspective. Agricultural and Forest Meteorology, 113(1-4):159-183.

Stannard, D. (1997). A theoretically based determination of bowen-ratio fetch requirements. Boundary-Layer Meteorology, 83(3):375-406.

Stull, R. (1988). An introduction to boundary layer meteorology. Springer. 
X - 54 GOOD, SODERBERG, WANG, \& CAYLOR: UNCERTAINTY IN MEASUREMENTS OF $\delta_{E T}$

Sturm, P. and A. Knohl (2010). Water vapor $\delta^{2} \mathrm{H}$ and $\delta^{18} \mathrm{O}$ measurements using off-axis integrated cavity output spectroscopy. Atmos. Meas. Technol, 3:67.

Sturm, P., W. Eugster, and A. Knohl (2012). Eddy covariance measurements of $\mathrm{CO}_{2}$ isotopologues with a quantum cascade laser absorption spectrometer. Agricultural and Forest Meteorology, 152(1):73-82.

Taylor, J. (1997). An introduction to error analysis: the study of uncertainties in physical measurements. University Science Books, Sausalito, CA, 2nd edition.

Wang, L., K. K. Caylor, and D. Dragoni (2009). On the calibration of continuous, highpercision $\delta^{18} \mathrm{O}$ and $\delta^{2} \mathrm{H}$ measurements using an off-axis integrated cavity output spectrometer. Rapid Communications in Mass Spectrometry, 23(4):530-536.

Wang, L., K. K. Caylor, J. C. Villegas, G. A. Barron-Gafford, D. Breshears, and T. E. Huxman (2010). Partitioning evapotranspiration across gradients of woody plant cover, assessment of a stable isotope technique. Geophysical Research Letters, 37(L09401):1-7.

Wang, L., S. Good, K. Caylor, and L. Cernusak (2012). Direct quantification of leaf transpiration isotopic composition. Agricultural and Forest Meteorology, 154:127-135.

Wang, X. and D. Yakir (2000). Using stable isotopes of water in evapotranspiration studies. Hydrological Processes, 14(8):1407-1421.

Wen, X., X. Sun, S. Zhang, G. Yu, S. Sargent, and X. Lee (2008). Continuous measurement of water vapor $\mathrm{D} / \mathrm{H}$ and ${ }^{18} \mathrm{O} /{ }^{16} \mathrm{O}$ isotope ratios in the atmosphere. Journal of Hydrology, $349(3-4): 489-500$.

Williams, D., W. Cable, K. Hultine, J. Hoedjes, E. Yepez, V. Simonneaux, S. Er-Raki, G. Boulet, H. De Bruin, A. Chehbouni, O. Hartogensis, and F. Timouk(2004). Evapotranspiration components determined by stable isotope, sap flow and eddy covariance 
GOOD, SODERBERG, WANG, \& CAYLOR: UNCERTAINTY IN MEASUREMENTS OF $\delta_{E T} \quad \mathrm{X}-55$

techniques. Agricultural and Forest Meteorology, 125(3-4):241-258.

Wingate, L., J. Ogée, M. Cuntz, B. Genty, I. Reiter, U. Seibt, D. Yakir, K. Maseyk, E. Pendall, M. Barbour, M., et al. (2009). The impact of soil microorganisms on the global budget of $\delta^{18} \mathrm{O}$ in atmospheric $\mathrm{CO}_{2}$. Proceedings of the National Academy of Sciences, 106(52):22411.

Wingate, L., J. Ogée, R. Burlett, A. Bosc, M. Devaux, J. Grace, D. Loustau, and A. Gessler, A. (2010). Photosynthetic carbon isotope discrimination and its relationship to the carbon isotope signals of stem, soil and ecosystem respiration. New Phytologist, $188(2): 576-589$.

G. Wohlfahrt, L. Hörtnagl, A. Hammerle, M. Graus, and A. Hansel (2009) Measuring eddy covariance fluxes of ozone with a slow-response analyzer Atmospheric Environment, 43(30):4570-4576.

Yakir, D. and X. Wang (1996). Fluxes of $\mathrm{CO}_{2}$ and water between terrestrial vegetation and the atmosphere estimated from isotope measurements. Nature, 380(6574):515-517.

Yakir, D. and L. Sternberg (2000). The use of stable isotopes to study ecosystem gas exchange. Oecologia, 123(3):297-311.

Yepez, E., D. Williams, R. Scott, and G. Lin (2003). Partitioning overstory and understory evapotranspiration in a semiarid savanna woodland from the isotopic composition of water vapor. Agricultural and Forest Meteorology, 119(1-2):53-68.

Yepez, E., T. Huxman, D. Ignace, N. English, J. Weltzin, A. Castellanos, and D. Williams (2005). Dynamics of transpiration and evaporation following a moisture pulse in semiarid grassland: a chamber-based isotope method for partitioning flux components. Agricultural and Forest Meteorology, 132(3-4):359-376. 
X - 56 GOOD, SODERBERG, WANG, \& CAYLOR: UNCERTAINTY IN MEASUREMENTS OF $\delta_{E T}$

\section{Appendix A: Estimation of Covariance Uncertainty}

We wish to express the uncertainty of a covariance calculation as a function of a random error associated with the scalar measurement. Let the vertical wind measurements, $\vec{w}$, be a vector of length $n$ with mean $\bar{w}$ and standard deviation $\sigma_{w}$. Similarly, let the scalar measurements, $\vec{c}$, be a vector of length $n$ with mean $\bar{c}$. Given $\vec{w}$ and $\vec{c}$ the sample covariance is

$$
\operatorname{Cov}(\vec{w}, \vec{c})=\frac{1}{n} \sum_{i=1}^{n}\left(w_{i}-\bar{w}\right)\left(c_{i}-\bar{c}\right)
$$

Random system noise, $\mathbf{Z}$, an independent and identically distributed random variable, is drawn from an unknown distribution with mean zero (i.e., the expected value of $\mathbf{Z}, \mathbb{E}[\mathbf{Z}]$ $=0$ ) and is added to each member of the scalar vector $\vec{c}$. As the random variable $\overrightarrow{\mathbf{Z}}$ now influences the covariance, the value of $\operatorname{Cov}(\vec{w}, \vec{c}+\overrightarrow{\mathbf{Z}})$ is itself a random variable, denoted by $\mathbf{Y}$. The random variable $\mathbf{Y}$ is then the covariance of the scalar signal with introduced noise and vertical wind measurement is given by:

$$
\mathbf{Y}=\operatorname{Cov}(\vec{w}, \vec{c}+\overrightarrow{\mathbf{Z}})=\frac{1}{n} \sum_{i=1}^{n}\left(w_{i}-\bar{w}\right)\left(c_{i}-\bar{c}+\mathbf{Z}_{i}\right)
$$


The variance of $\mathbf{Y}$, formally defined as $\operatorname{Var}[\mathbf{Y}]=\mathbb{E}\left[(\mathbf{Y}-\mathbb{E}[\mathbf{Y}])^{2}\right]$, is then derived using the properties of variance as:

$$
\begin{aligned}
\operatorname{Var}(\mathbf{Y}) & =\operatorname{Var}\left(\frac{1}{n} \sum_{i=1}^{n}\left(w_{i}-\bar{w}\right)\left(c_{i}-\bar{c}+\mathbf{Z}_{i}\right)\right) \\
& =\operatorname{Var}\left(\operatorname{Cov}(\vec{w}, \vec{c})+\frac{1}{n} \sum_{i=1}^{n}\left(w_{i}-\bar{w}\right) \mathbf{Z}_{i}\right) \\
& =\frac{1}{n^{2}} \operatorname{Var}\left(\sum_{i=1}^{n}\left(w_{i}-\bar{w}\right) \mathbf{Z}_{i}\right) \\
& =\frac{1}{n^{2}} \sum_{i=1}^{n} \operatorname{Var}\left(w_{i} \mathbf{Z}_{i}\right)-\bar{w}^{2} \operatorname{Var}\left(\mathbf{Z}_{i}\right) \\
& =\frac{1}{n^{2}} \sum_{i=1}^{n} \bar{w}^{2} \operatorname{Var}\left(\mathbf{Z}_{i}\right)+(\mathbb{E}[\mathbf{Z}])^{2} \sigma_{w}^{2} \\
& +\sigma_{w}^{2} \operatorname{Var}\left(\mathbf{Z}_{i}\right)-\bar{w}^{2} \operatorname{Var}\left(\mathbf{Z}_{i}\right) \\
= & \frac{1}{n^{2}} \sum_{i=1}^{n} \sigma_{w}^{2} \operatorname{Var}\left(\mathbf{Z}_{i}\right) \\
= & \frac{1}{n} \sigma_{w}^{2} \operatorname{Var}(\mathbf{Z})
\end{aligned}
$$

Following Goodman [1962] we expand $\operatorname{Var}\left(w_{i} \mathbf{Z}_{i}\right)$ with the assumption that $\mathbf{Z}$ is independent of $\vec{w}$. Thus we find that the variance of an estimated covariance with random noise added to the scalar term is equal to the variance of the first member multiplied by the variance of the noise term divided by the number of samples.

\section{Appendix B: Calculation of Individual Isotopologues from ICOS data}

The mixing ratios of individual isotopolouges were calculated from the Los Gatos Inc.

ICOS output. In the case of hydrogen, we assume vapor only containes the two most abundant isotopologues, ${ }^{2} \mathrm{H}$ and ${ }^{1} \mathrm{H}$. Therefore $\chi_{v}=\frac{1}{2}\left({ }^{\alpha} \chi_{v}+{ }^{\beta} \chi_{v}\right)$, where $\alpha$ refers to ${ }^{2} \mathrm{H}$ and refers to $\beta={ }^{1} \mathrm{H}$. The ICOS system records the total mixing ratio which was converted $\chi_{v}$ (the dry molar mixing ratio) and atomic isotope ratio, ${ }^{\alpha / \beta} R_{v}$, in the internal chamber. 
X - 58 GOOD, SODERBERG, WANG, \& CAYLOR: UNCERTAINTY IN MEASUREMENTS OF $\delta_{E T}$

1047 are:

$$
\begin{aligned}
& { }^{\alpha} \chi_{v}=2 \chi_{v} \frac{{ }^{\alpha / \beta} R}{1+{ }^{\alpha / \beta} R} \\
& { }^{\beta} \chi_{v}=2 \chi_{v} \frac{1}{1+{ }^{\alpha / \beta} R}
\end{aligned}
$$

For the case of oxygen isotopologues, the concentration of ${ }^{17} \mathrm{O}$ is considered in addition to ${ }^{16} \mathrm{O}$ and ${ }^{18} \mathrm{O}$. Therefore we have $\chi_{v}={ }^{\alpha} \chi_{v}+\chi^{\gamma}+{ }^{\beta} \chi_{v}$, where $\alpha$ refers to ${ }^{18} \mathrm{O}, \gamma$ refers to ${ }^{17} \mathrm{O}$, and $\beta$ refers to ${ }^{16} \mathrm{O}$. We use the following relationship

$$
\frac{R^{\gamma / \beta}}{R_{s t d}^{\gamma / \beta}}=\left(\frac{{ }^{\alpha / \beta} R}{\alpha / \beta} R_{s t d}\right)^{\lambda}
$$

to estimate the value of ${ }^{\gamma / \beta} R$, with $\lambda=0.52$ [Miller, 2002] and VSMOW ratios from 1050 De Laeter et al. [2003]. We note that ${ }^{\gamma / \beta} R={ }^{\gamma} \chi /{ }^{\beta} \chi_{v}$, therefore we have $\chi_{v}={ }^{\alpha} \chi_{v}+{ }^{\beta}$ 1051 $\chi_{v}\left(1+{ }^{\gamma / \beta} R\right)$. The mixing ratios of ${ }^{\alpha} \chi_{v}$ and ${ }^{\beta} \chi_{v}$ for oxygen isotopologues are then:

$$
\begin{aligned}
{ }^{\alpha} \chi_{v} & =\chi_{v} \frac{{ }^{\alpha / \beta} R}{1+{ }^{\alpha / \beta} R+\gamma / \beta} R \\
{ }^{\beta} \chi_{v} & =\chi_{v} \frac{1}{1+{ }^{\alpha / \beta} R+\gamma / \beta} R
\end{aligned}
$$




\section{Figures And Tables}

Table 1. Average estimated standard deviation of random errors, $\left\langle\epsilon_{\delta}\right\rangle[\%$ ], and average uncertainty, $\left\langle\sigma_{\delta_{E T}}\right\rangle[\%$ ], for different methods and ICOS configurations from 80 half-hour blocks. The ICOS system and number of data points used in each block are also listed. Results of laboratory calibrations with known vapor sources for ICOS1 and ICOS2 are also given.

\begin{tabular}{lcr|rr|rc}
\multicolumn{3}{c}{ Configuration } & \multicolumn{2}{c}{${ }^{2} \mathbf{H}$} & \multicolumn{2}{c}{${ }^{18} \mathbf{O}$} \\
Method & ICOS & $\mathrm{N}$ & $\left\langle\epsilon_{\delta}\right\rangle$ & $\left\langle\sigma_{\delta_{E T}}\right\rangle$ & $\left\langle\epsilon_{\delta}\right\rangle$ & $\left\langle\sigma_{\delta_{E T}}\right\rangle$ \\
\hline $\mathrm{KP}_{22.5}$ & 1 & 1800 & 2.20 & 4.62 & 0.87 & 1.78 \\
$\mathrm{KP}_{\overline{9}: \overline{22.5}}$ & 2 & 4 & 17.72 & 78.91 & 5.83 & 24.91 \\
$\mathrm{KP}_{9: 22.5}$ & 2 & 1200 & 2.53 & 6.15 & 0.62 & 1.42 \\
$\mathrm{FG}_{\overline{9}: \overline{22.5}}$ & 2 & 4 & 18.14 & 80.99 & 5.89 & 24.69 \\
$\mathrm{FG}_{9: 22.5}$ & 2 & 1200 & 2.53 & 6.13 & 0.62 & 1.42 \\
$\mathrm{EC}_{22.5}(\mathrm{ML})$ & 1 & 1800 & 6.85 & 66.24 & 2.71 & 24.60 \\
$\mathrm{EC}_{22.5}(\mathrm{FS})$ & 1 & 1800 & 4.15 & 37.77 & 1.97 & 15.23 \\
Lab calibration & 1 & & 2.21 & - & 0.60 & - \\
Lab calibration & 2 & & 1.61 & - & 0.73 & -
\end{tabular}

Table 2. Tabulated relationships between $\delta_{E T}$ values calculated with each method from 80 half-hour blocks. Relationships are expressed in the form $y=\mathrm{A}+\mathrm{B} x[\% 0]$, with root mean squared errors [\%o] in parentheses. Bold regression trends are plotted in Figure 8.

\begin{tabular}{|c|c|c|c|c|c|c|}
\hline$\downarrow y \backslash x \rightarrow$ & $\mathrm{KP}_{22.5}$ & $\mathrm{KP}_{\overline{9}: \overline{22.5}}$ & $\mathrm{KP}_{9: 22.5}$ & $\mathrm{FG}_{\overline{9}: \overline{22.5}}$ & $\mathrm{FG}_{9: 22.5}$ & $\mathrm{EC}_{22.5}$ \\
\hline $\mathrm{KP}_{22.5}$ & & $-34.7+.12 x(48)$ & $-26.8+.43 x(43)$ & $-34.3+.12 x(48)$ & $-26.9+.43 x(43)$ & $-37.4+.39 x(41)$ \\
\hline $\mathrm{KP}_{\overline{9}: \overline{22.5}}$ & $-23.5+.66 x(114)$ & & $-1.4+1.54 x(78)$ & $3.2+.99 x(18)$ & $-1.6+1.54 x(78)$ & $-49.1+.11 x(119)$ \\
\hline $\mathrm{KP}_{9: 22.5}$ & $-7.8+.59 x(50)$ & $-13.2+.37 x(38)$ & & $-11.9+.37 x(39)$ & $-0.1+1.0 x(1)$ & $-30.4+.12 x(58)$ \\
\hline $\mathrm{FG}_{\overline{9}: \overline{22.5}}$ & $-27.2+.66 x(114)$ & $-4.4+.98 x(18)$ & $-5.4+1.53 x(78)$ & & $-5.6+1.52 x(79)$ & $-52.6+.11 x(118)$ \\
\hline $\mathrm{FG}_{9: 22.5}$ & $-7.7+.59 x(50)$ & $-13.2+.37 x(38)$ & $0+1.0 x(1)$ & $-11.9+.37 x(39)$ & & $-30.3+.12 x(58)$ \\
\hline $\mathrm{EC}_{22.5}$ & $8.7+.51 x(48)$ & $-11.1+.02 x(56)$ & $-8.8+.11 x(56)$ & $-11+.02 x(56)$ & $-8.8+.11 x(56)$ & \\
\hline \multicolumn{7}{|c|}{$\delta_{E T}{ }^{18} \mathrm{O} \quad[\% 0]$} \\
\hline $\mathrm{KP}_{22.5}$ & & $-1.9-.14 x(18)$ & $-3-.29 x(18)$ & $-1.9-.14 x(18)$ & $-3-.29 x(18)$ & $-2.8+.10 x(20)$ \\
\hline $\mathrm{KP}_{\overline{9}: \overline{22.5}}$ & $-12.8-.74 x(41)$ & & $3.3+1.6 x(29)$ & $-0.1+1.02 x(4)$ & $3.3+1.6 x(29)$ & $-14.1+.13 x(43)$ \\
\hline $\mathrm{KP}_{9: 22.5}$ & $-10-.34 x(19)$ & $-5.5+.35 x(13)$ & & $-5.5+.36 x(13)$ & $0+1.0 x(0)$ & $-12+.19 x(20)$ \\
\hline $\mathrm{FG}_{\overline{9}: \overline{22.5}}$ & $-12.5-.73 x(40)$ & $0+.98 x$ & $3.5+1.59 x(28)$ & & $3.5+1.59 x(28)$ & $-13.8+.13 x(42)$ \\
\hline $\mathrm{FG}_{9: 22.5}$ & $-10-.34 x(19)$ & $-5.5+.35 x(13)$ & $0+1.0 x(0)$ & $-5.5+.36 x(13)$ & & $-12+.19 x(20)$ \\
\hline $\mathrm{EC}_{22.5}$ & $10.2+.12 x(22)$ & $11.5+.04 x(23)$ & $13.5+.25 x(23)$ & $11.5+.04 x(23)$ & $13.5+.25 x(23)$ & \\
\hline
\end{tabular}




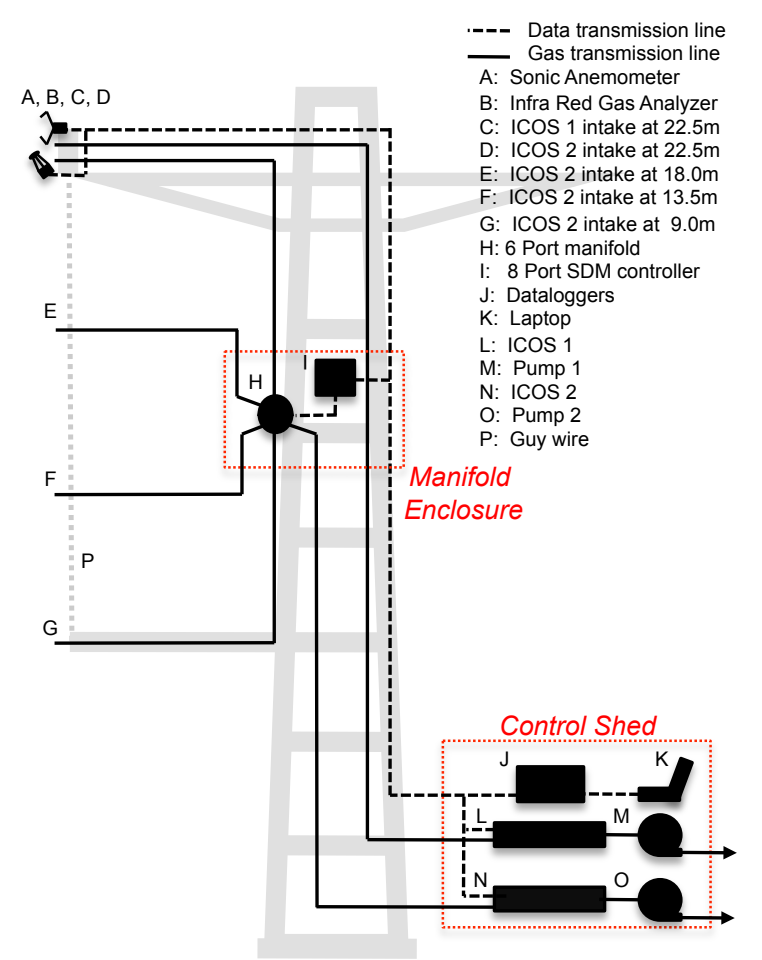

Figure 1. Schematic of the equipment configuration on the eddy covariance tower at the Mpala Research Center, Kenya. Two commercial water vapor isotope analyzers ( $\mathrm{L}$ and $\mathrm{N}$ ) are connected to intakes at multiple heights (C and D-G), with the upper most intake collocated with a sonic anemometer (A) and infra-red gas analyzer (B). 

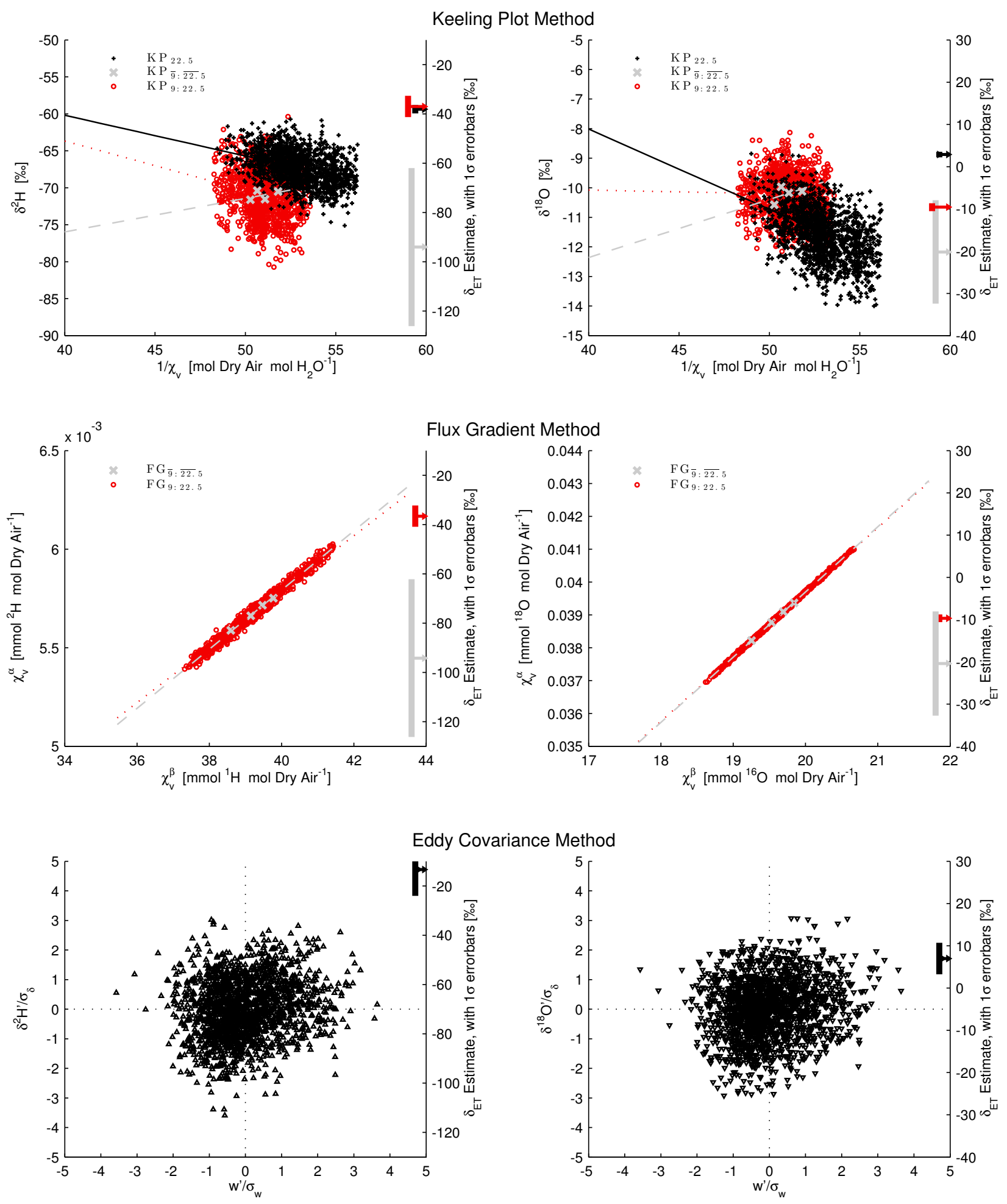
Figure 2. Example plots showing the different configurations and methods used in this study to calculate $\delta_{E T}$ for the stable isotopes of hydrogen (left plots) and oxygen (right plots). Calculations are made using data from one height at 22.5m (subscript 22.5), data from four heights at $9,14.5,18$, and $22.5 \mathrm{~m}$ (subscript 9:22.5), and data from the same four heights but with all data at each height averaged $(\overline{9}: \overline{22.5})$, see methods section for complete description. Individual data points used in the calculations shown are from May 7th 2011 at 14:00-14:30hrs, and the calculated values of $\delta_{E T}$ with $1 \sigma_{\delta_{E T}}$ error bars are shown on the right axis of each plot. The Keeling plot method (top plots) estimates $\delta_{E T}$ through linear regression to the vertical axis. The flux gradient method (middle plots) estimates $\delta_{E T}$ from the slope of a linear regression of ${ }^{\alpha} \chi_{v}$ against ${ }^{\beta} \chi_{v}$. With the eddy covariance method (bottom plots), the value of $\delta_{E T}$ is calculated from the covariance of $w$ and $\delta_{v}$. 

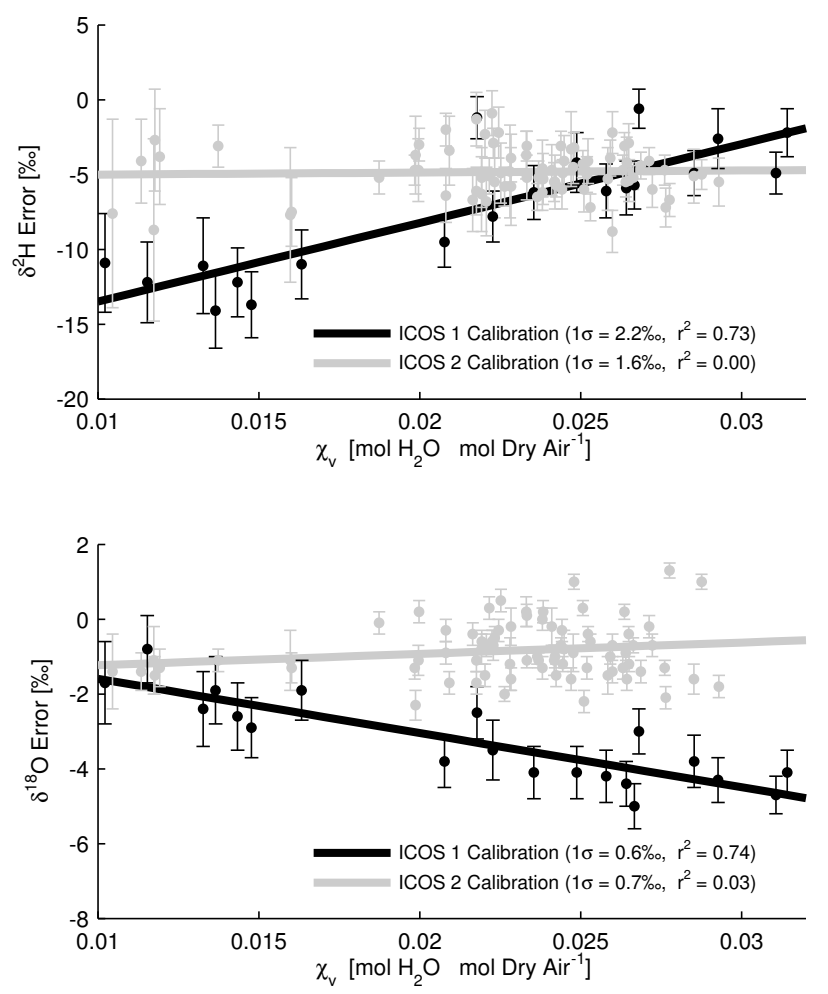

Figure 3. Calibration results for ICOS1 and ICOS2. Calibrated $1 \sigma$ values for ICOS1 are $2.20 \%$ for ${ }^{2} \mathrm{H}$ and $0.60 \%$ for ${ }^{18} \mathrm{O}$. Calibrated $1 \sigma$ values for ICOS2 are $1.61 \%$ for ${ }^{2} \mathrm{H}$ and $0.73 \%$ o for ${ }^{18} \mathrm{O}$. 


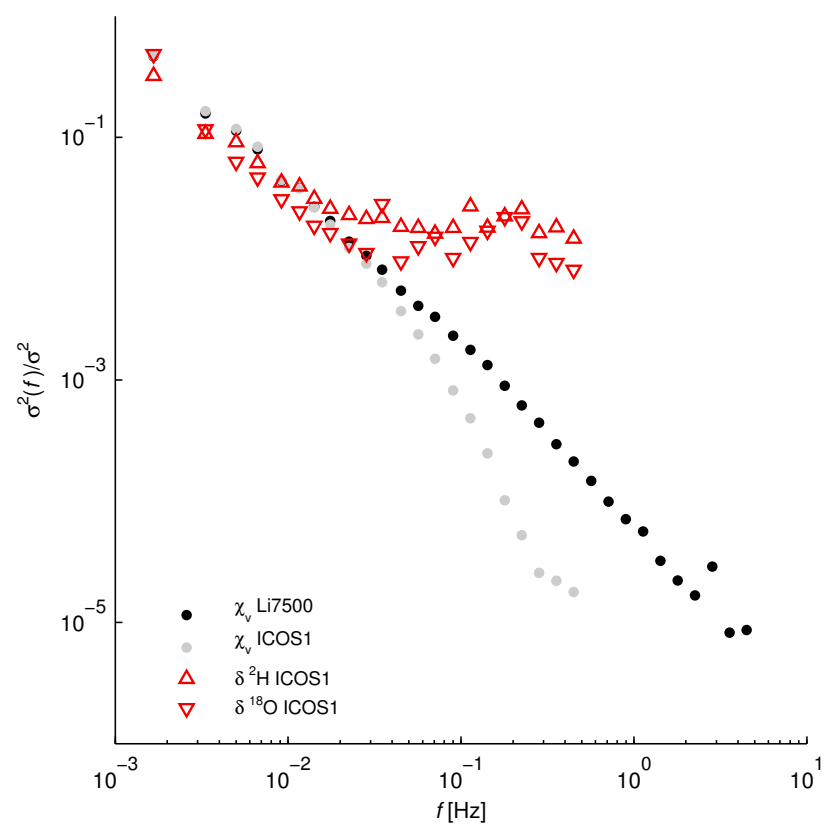

Figure 4. Normalized power spectra for bulk water vapor $\left(\chi_{v}\right)$ and its isotopic composition $\left(\delta^{2} \mathrm{H}\right.$ and $\left.\delta^{18} \mathrm{O}\right)$. Spectra are computed from 10 minute intervals for all 80 selected time blocks then averaged. Spectra were then bin averaged using 10 logarithmically spaced intervals per decade. 

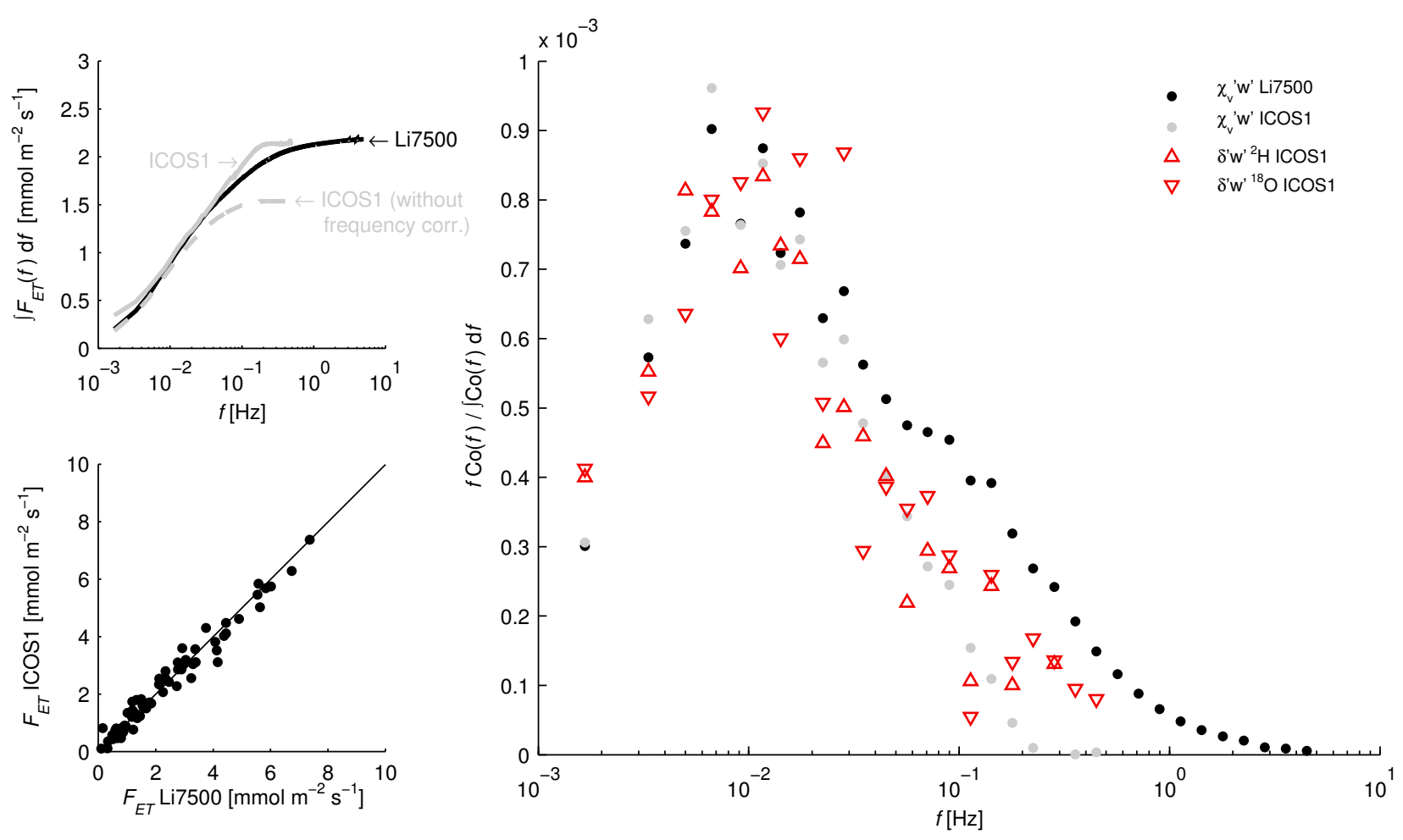

Figure 5. Integral cospectra of water vapor flux (top left), final corrected flux estimates (bottom left) and normalized cospectra of water vapor fluxes and isoforcings (right). Cospectra are computed from 10 minute intervals for all 80 selected time blocks then averaged. The cospectra were then bin averaged using 10 logarithmically spaced intervals per decade. 


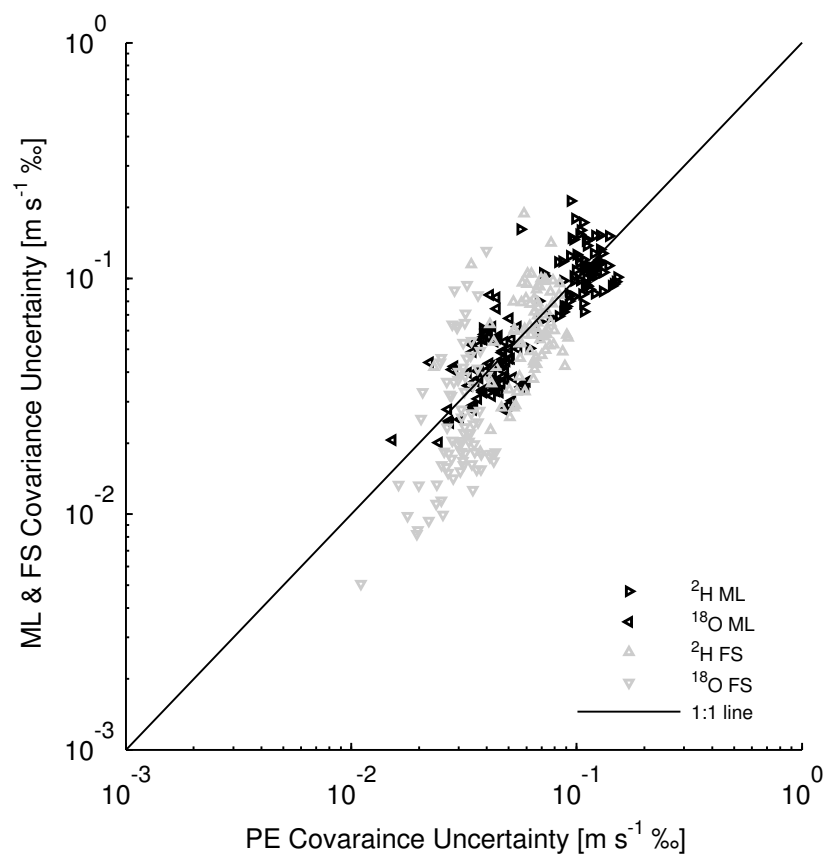

Figure 6. Comparison of covariance uncertainty estimator of Mann and Lenschow [1994] (ML, black triangles) and Finkelstein and Sims [2001] (FS, gray triangles) with that found by propagation of random errors (PE, equation 22). Values for $\left\langle\epsilon_{\delta}\right\rangle$, from Table 1, were estimated by a non-linear regression fit between the ML and FS estimators with equation (22). 


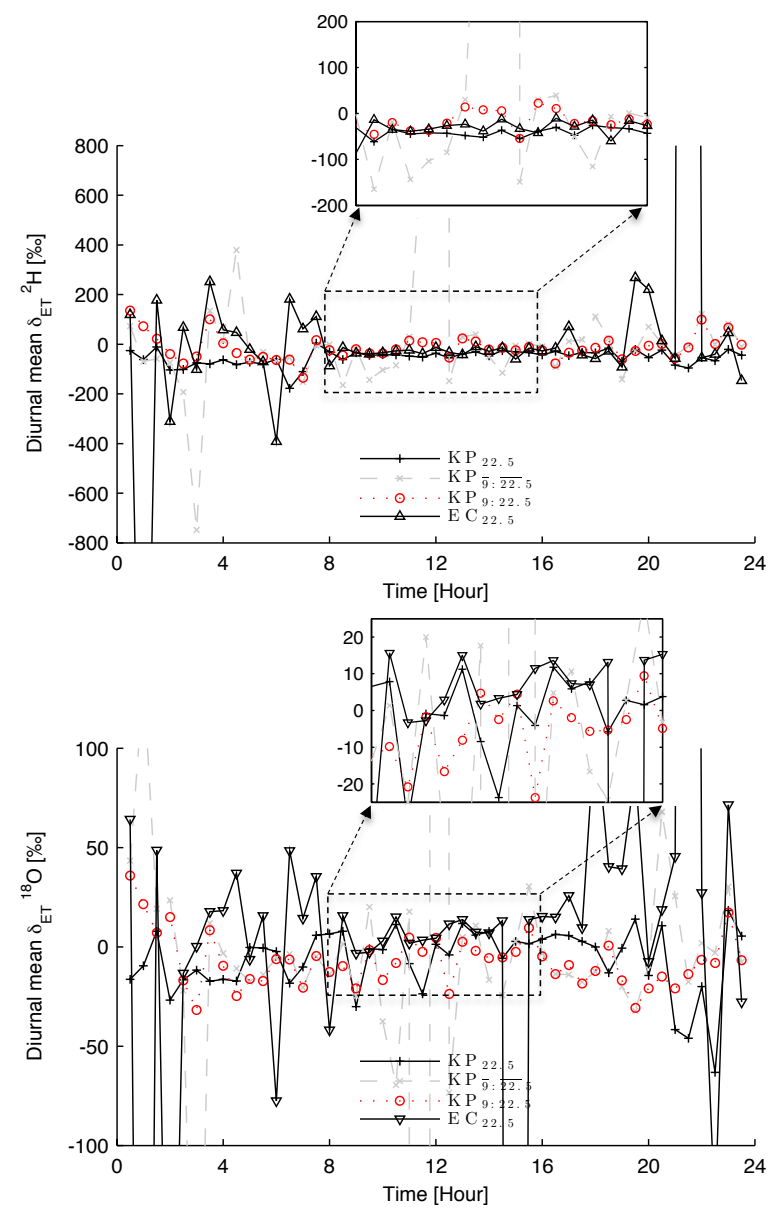

Figure 7. Mean diurnal cycle of isotope flux composition for ${ }^{2} \mathrm{H}$ and ${ }^{18} \mathrm{O}$. Each point is the average of all 30-minute blocks for that half hour from May 6 to May 11, 2011. Inset figures depict mid-day (8:00AM to 4:00PM) values. Flux-gradient method results are identical to the Keeling plot results and are not show. 

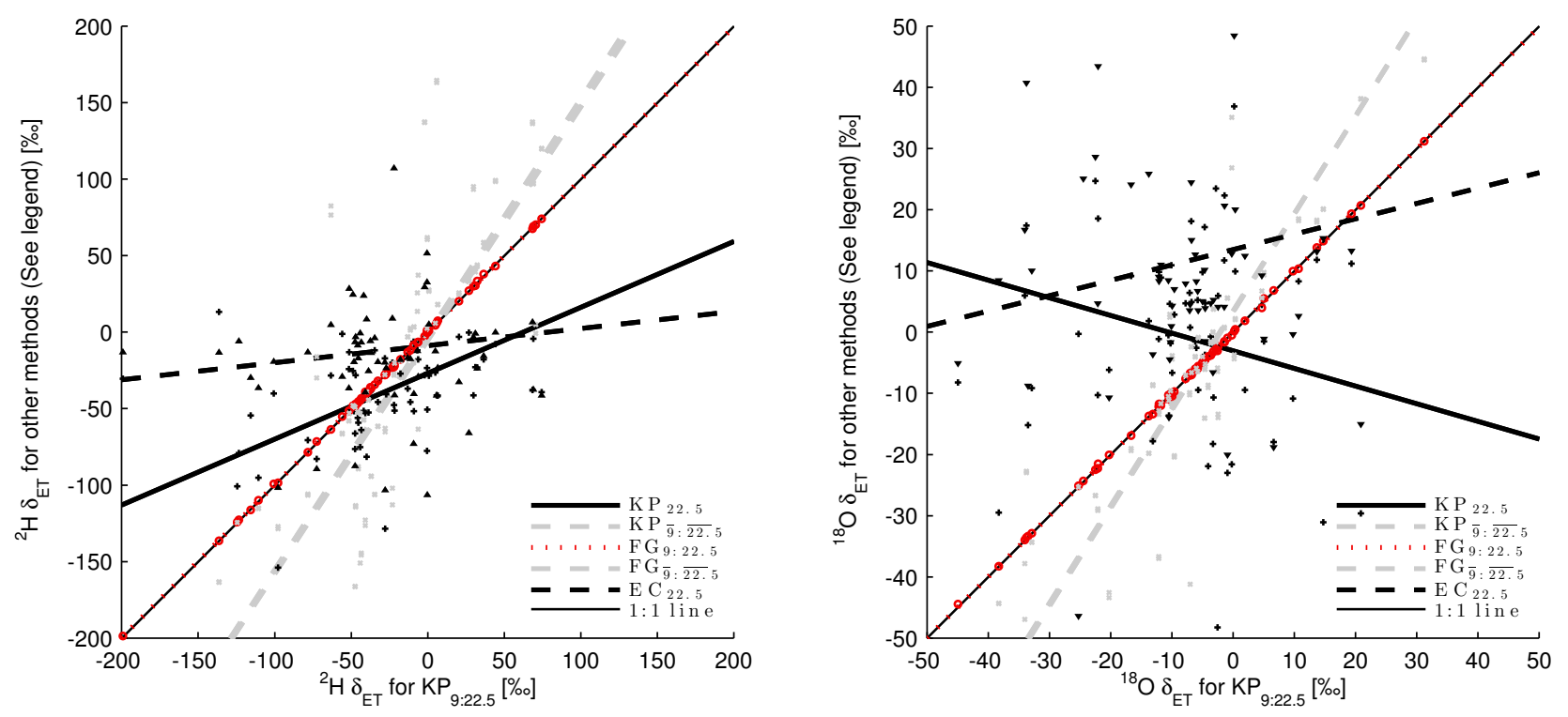

Figure 8. Comparison between $\delta_{E T}$ calculated using all the profile points of ICOS2 with a Keeling plot $\left(\mathrm{KP}_{9: 22.5}\right)$ and other methods. For both hydrogen and oxygen isotopes, the Keeling plot and flux gradient estimates $\left(\mathrm{FG}_{9: 22.5}\right.$, red o's) of $\delta_{E T}$ are nearly identical when using the ICOS2 profile data individually (red dotted line on top of 1:1 line). The methods using the height averaged values $\left(\mathrm{KP}_{\overline{9}: \overline{22.5}}\right.$ and $\mathrm{FG}_{\overline{9}: \overline{22.5}}$, gray $\times$ 's) also yield similarly biased $\delta_{E T}$ values relative to the profile methods with all points treated individually. Values from methods using ICOS1 $\left(\mathrm{KP}_{22.5}\right.$ and $\mathrm{EC}_{22.5}$, black $\boldsymbol{\Delta}$ 's and +'s) are weakly correlated with those of ICOS2. 

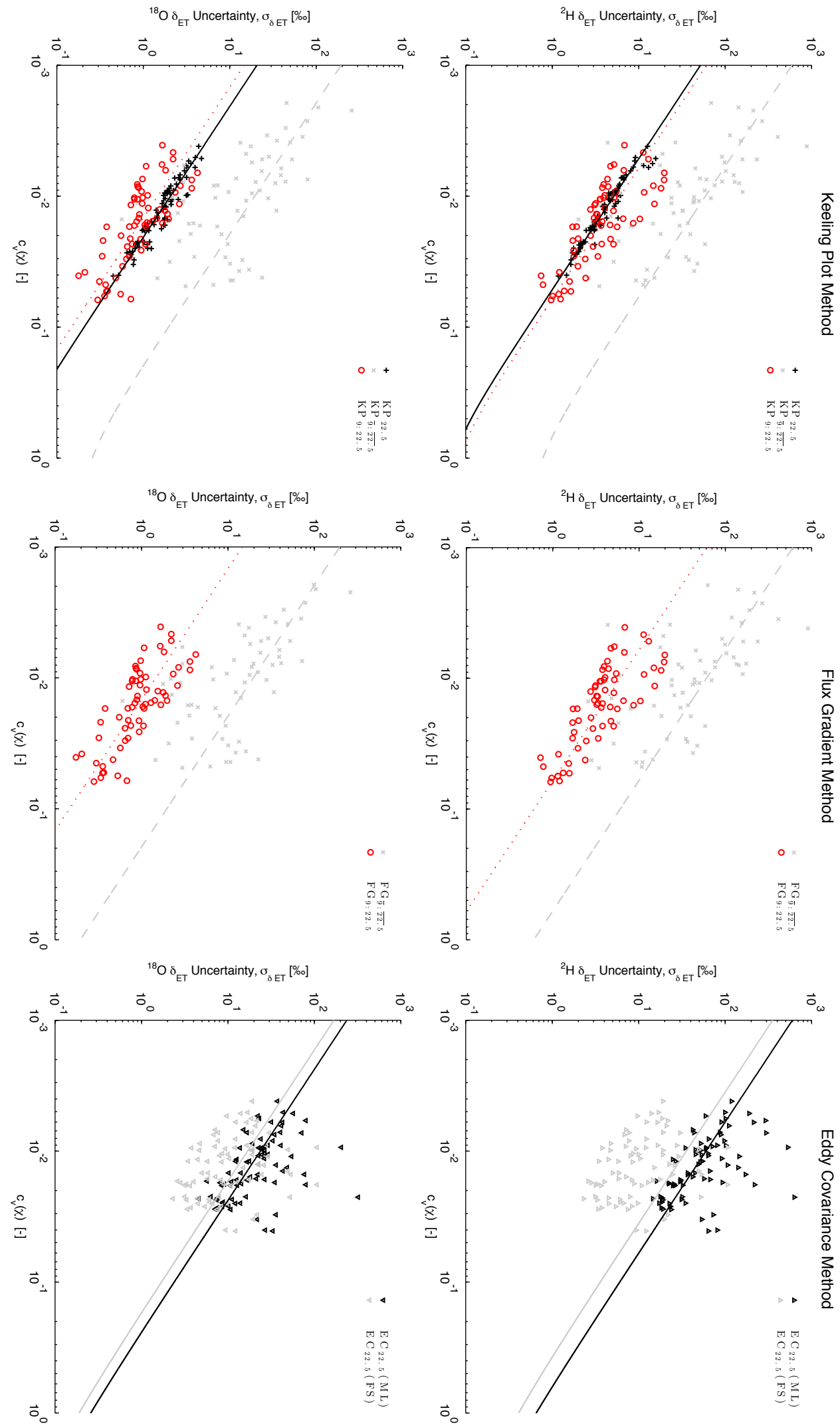
Figure 9. Uncertainty in estimates of the isotopic composition of evapotranspiration, $\sigma_{\delta_{E T}}$ $[\% 0]$, as a function of the coefficient of variation of atmospheric water vapor, $c_{v}(\chi)[-]$, for Keeling plot (left), flux gradient (middle), and eddy covariance (right) techniques. Individual values of uncertainty estimates of $\delta_{E T}$ for ${ }^{2} \mathrm{H}$ and ${ }^{18} \mathrm{O}$ are calculated using least squares regression techniques of equations (12)-(15) and the Mann and Lenschow [1994] and Finkelstein and Sims [2001] methods. Regression lines are plotted using equations (17), (19), and (23) with $\left\langle\epsilon_{\delta}\right\rangle$ values from Table 1. The mean values of $r_{w^{\prime} \chi_{v}^{\prime}}$, and $\sigma_{\delta}$ were used in equation (23) to plot the $\sigma_{\delta}(E C)$ regression. 


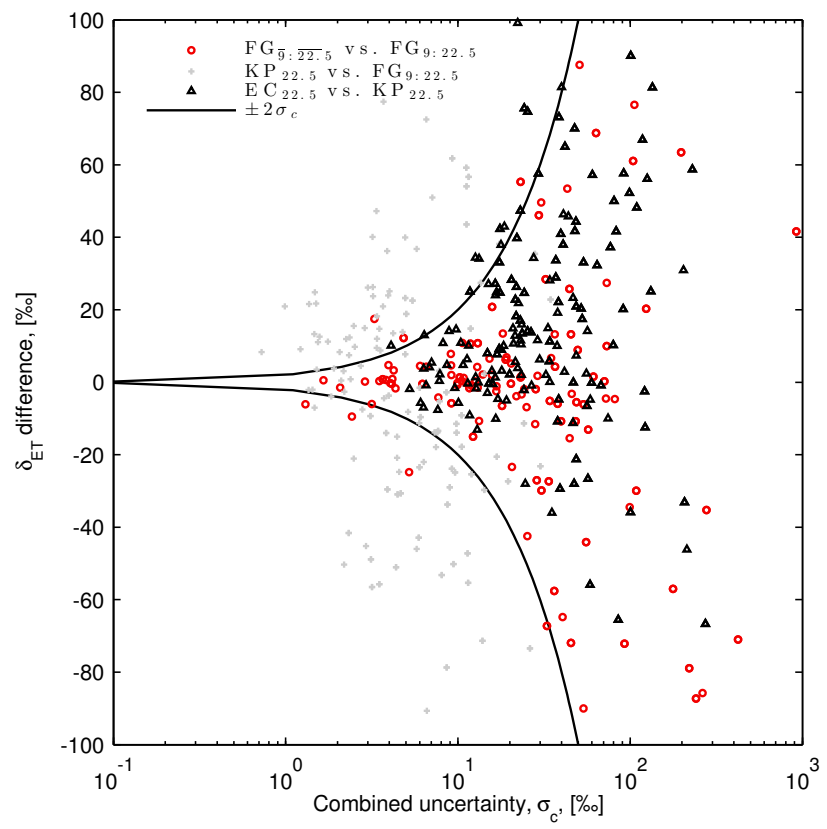

Figure 10. Difference in $\delta_{E T}$ estimates as a function of combined uncertainty, $\sigma_{c}$. Combined uncertainty is the sum of the uncertainties associated with each method. Comparison between methods on each ICOS system and the same heights, FG $\overline{\overline{9}: \overline{22.5}}$ versus $\mathrm{FG}_{9: 22.5}$ (red ○'s) and $\mathrm{KP}_{22.5}$ versus $\mathrm{EC}_{22.5}$ (black $\mathbf{\Delta}$ 's), mostly fall within two standard deviations of the combined uncertainty with differences diminishing at lower $\sigma_{c}$ values. The comparison of results between observations at $22.5 \mathrm{~m}$ and centered at $13.5 \mathrm{~m}, \mathrm{KP}_{9: 22.5}$ versus $\mathrm{KP}_{22.5}$ (gray $\times$ 's), yield larger differences in $\delta_{E T}$ estimates denoting changes in the total flux composition. 


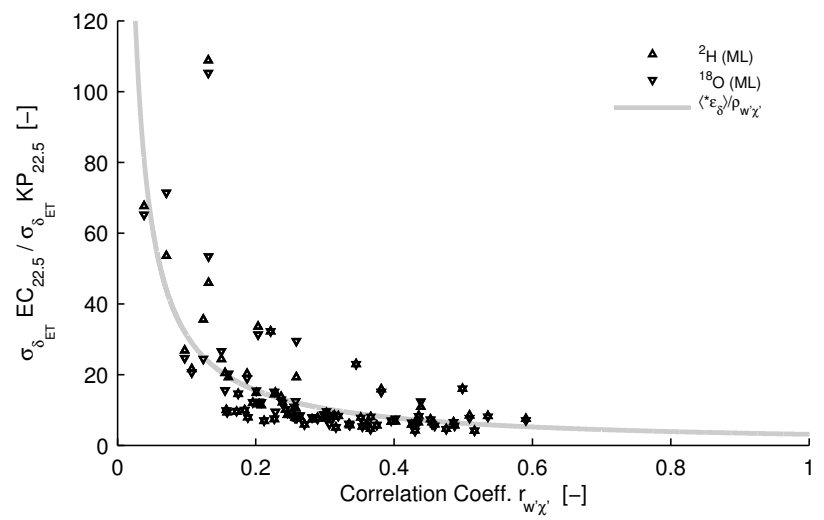

Figure 11. Ratio of expected uncertainty of the eddy covariance method, $\sigma_{\delta_{E T}}\left(\mathrm{EC}_{22.5}\right)$, to that of the Keeling plot method, $\sigma_{\delta_{E T}}\left(\mathrm{KP}_{22.5}\right)$, as a function of the correlation coefficient of vertical wind speed and water vapor mixing ratio, $r_{w^{\prime}} \chi_{v}^{\prime}$. The EC method is always less precise than the KP method, with ratio values $>1$ consistently, and is proportional to $1 / r_{w^{\prime}} \chi_{v}^{\prime}$ as given by equation (27) (with $\left\langle{ }^{*} \epsilon_{\delta}\right\rangle=3.1$ from Table 1 ).

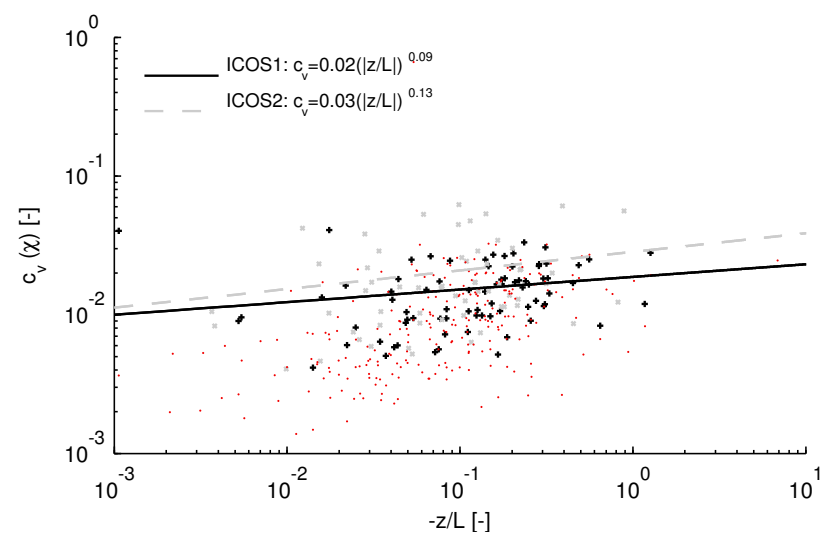

Figure 12. Coefficient of variation in atmospheric water vapor, $c_{v}\left(\chi_{v}\right)$, as a function of atmospheric stability, $-z / L$. Values of $c_{v}\left(\chi_{v}\right)$ from ICOS1 data (solid line and +'s) are calculated from all data collected at $22.5 \mathrm{~m}$ during each $30 \mathrm{~min}$ averaging block. $c_{v}$ values from ICOS2 data (dashed line and $\times$ 's) are calculated using all heights for each $30 \mathrm{~min}$ period. Red points are $c_{v}$ values calculated individually from each 7.5 minute period at the different profile heights. 